\title{
Challenges and Paradoxes in Decolonising HCI: A Critical Discussion
}

\author{
Shaimaa Lazem ${ }^{1}$ (D), Danilo Giglitto ${ }^{2}$, Makuochi Samuel Nkwo ${ }^{3}$, Hafeni Mthoko ${ }^{4}$, \\ Jessica Upani ${ }^{5} \&$ Anicia Peters ${ }^{6}$ \\ ${ }^{1}$ City of Scientific Research and Technology Applications, New Borg El-Arab City, Alexandria , Egypt ( \\ E-mail: slazem@srtacity.sci.eg); *2Centre for Culture, Media and Society, Sheffield Hallam University, \\ Sheffield,UK (E-mail: d.giglitto@shu.ac.uk); ${ }^{3}$ Department of Computer Science, Ebonyi State \\ University Abakaliki, Abakaliki, Nigeria; ${ }^{4}$ University of Namibia, Windhoek, Namibia; ${ }^{5}$ Faculty of \\ Computing and Informatics, Namibia University of Science and Technology, Windhoek, Namibia; \\ ${ }^{6}$ University of Namibia, Windhoek, Namibia
}

Accepted: 3 March 2021

\begin{abstract}
The preponderance of Western methods, practices, standards, and classifications in the manner in which new technology-related knowledge is created and globalised has led to calls for more inclusive approaches to design. A decolonisation project is concerned with how researchers might contribute to dismantling and re-envisioning existing power relations, resisting past biases, and balancing Western heavy influences in technology design by foregrounding the authentic voices of the indigenous people in the entire design process. We examine how the establishment of local Global South HCI communities (AfriCHI and ArabHCI) has led to the enactment of decolonisation practices. Specifically, we seek to uncover how decolonisation is perceived in the AfriCHI and ArabHCI communities as well as the extent to which both communities are engaged with the idea of decolonisation without necessarily using the term. We drew from the relevant literature, our own outsider/insider lived experiences, and the communities' responses to an online anonymised survey to highlight three problematic but interrelated practical paradoxes: a terminology, an ethical, and a microcolonisation paradox. We argue that these paradoxes expose the dilemmas faced by local non-Western researchers as they pursue decolonisation thinking. This article offers a blended perspective on the decolonisation debate in $\mathrm{HCI}, \mathrm{CSCW}$, and the practice-based CSCW scholarly communities and invites researchers to examine their research work using a decolonisation lens.
\end{abstract}

Key Words:: Decolonisation, Post-colonial computing, Decolonial computing, HCI4D, Marginalised communities, Arab HCI, AfricanHCI, Local HCI communities, ICT4D

\section{Introduction}

In the past few years, there has been a growing number of research efforts from Western researchers that are critical of the Western domination of the global HCI discourse, advocating the need for more inclusive approaches to design (Bardzell 2010; Bardzell and Bardzell 2016; Dell and Kumar 2016; Dourish and Mainwaring 
2012; Keyes et al. 2019; Irani and Dourish 2009; Ogbonnaya-Ogburu et al. 2020; Philip et al. 2012; Schlesinger et al. 2017).

Central to this article is the work of postcolonial computing scholars. Dourish and Mainwaring (2012) offer a post-colonial criticism for ubiquitous computing based on the argument that new technology-related knowledge is being produced in and centered around Western research hubs. The fact that most bases for innovation are located in Western contexts is aggravated by how technological systems, including practices, standards, and classifications, tend to aspire to universality. This means that very often, technological standards are defined in one part of the world and then globalised. These standards are tailored to the experiences of the people in the part of the world in which they were defined, potentially ignoring or underrepresenting the rest. One way to tackle this skewed cross-cultural representation would be to recognise the historical specificities of local contexts and adopt cultural sensitivities rather than presuming a global authority in terms of technological systems (Dourish and Mainwaring 2012; Irani et al. 2010).

Parallel to these Western-originated calls-for-action, non-Western researchers have been producing efforts towards imagining a better future for HCI studies and designs in the Global South through the establishment of various local HCI (Alabdulqader et al. 2017; Bidwell 2016; Lazem and Dray 2018; Peters et al. 2019; Winschiers-Theophilus and Bidwell 2013) and social intervention scholarly attempts (Nkwo 2019; Nkwo and Orji 2019), which have been locally designed to tackle local problems. Key to these efforts is capturing the authentic voices of indigenous African and Arab communities in technology design, and being critical of the domination of Western approaches for designs in non-Western contexts. We will argue that such communities lead a decolonising wave by bringing the body politics and geopolitics of knowledge to the foreground in the design discourse (Ali 2016).

As this article is set to deal with complex concepts and abstractions, we believe that it is important to preemptively clarify the terminology we adopted. We use the terms "West" and "Western" to refer to adopted systems of knowledge that emerged in Euro-US academia, with the underlying assumption that knowledge is not neutral as it echoes the worldview of where it was generated (Torretta and Reitsma 2019). These systems of knowledge transcend geographical borders and, as such, can be adopted anywhere. Western knowledge can and is adopted in non-Western research contexts. Hereafter, we use the terms "non-Western" and "local" interchangeably. We use "colonisation" to refer to a more or less subtle or indirect imposition of certain worldviews, prescription of certain solutions and methods, and/or legitimisation of certain forms of accepted knowledge. We do not promote the idea that an approach or a method is colonising in itself. Rather, as the decolonisation literature teaches us, we promote the necessity of a serious consideration of the interplay between who, where, and to whom, and how certain methods or approaches are applied in a way that can lead to a wave of neo-colonisation (Torretta and 
Reitsma 2019). We, therefore, do not reject, dismiss, or label Western methods as colonising in and of themselves.

Another preemptive clarification concerns the use of the term "decolonisation". As we shall see later, this term is not generally adopted by the communities we engaged with to write this article, AfriCHI and ArabHCI. The term was used to frame the organisation and planning of the first AfriCHI conference (Bidwell 2016), and then used to discuss ArabHCI efforts (Giglitto et al. 2018). It is worth mentioning that, to the best of our knowledge, the word "decolonisation" does not have any corresponding term in Arab or African dominant languages. The lack of adoption of the term "decolonisation" from AfriCHI and ArabHCI communities may lead to an ungrounded expectation that both communities must engage with this Westerngenerated term in order to partake in the discourse about promoting local knowledge. Concerned that the voices of the non-Western researchers would go unnoticed, we were motivated to look into the historical progression of the term and the insights it may bring to technology design and research. Our aim is to use decolonisation as a lens to retrospectively inspect our own and AfriCHI and ArabHCI communities' efforts by exploring the extent to which the term is conceptualised and used in both communities. It is also worth noting that our choice to focus on these communities solely stems from our direct experiences with both, and it is not meant to privilege them over other local HCI communities.

A certain degree of paradigmatic separation between Western and non-Western (or the center and periphery as we will refer to this dichotomy later) is not without consequences on academic research as it is evidenced by Kou et al. (2018). In their analysis of $306 \mathrm{CHI}$ papers between 2013 and 2016, differences in titling patterns and in the level of contextual details were found between papers describing studies carried out in Western and non-Western contexts, where authors of the latter had to be specific and detailed about their study contexts. They warned that this tacitly biased academic tradition considers knowledge produced by Western studies as the normal and universally applicable, while it tends to frame certain non-Western contexts as somewhat exotic. This bias may put non-Western researchers at a disadvantage as the credibility of their local knowledge is judged through Western experts' "normal" worldviews. To put it using the postcolonial scholar Edward Said's words:

'The Orient and Islam have a kind of extrareal, phenomenologically reduced status that puts them out of reach of everyone except the Western expert. From the beginning of Western speculation about the Orient, the one thing the Orient could not do was to represent itself. Evidence of the Orient was credible only after it had passed through and been made firm by the refining fire of the Orientalist's work.' (Said 2014,. p. 283).

Decolonial computing is a term that was put together by Ali (2014) to describe a critical project that aims at 'interrogating who is doing computing, where they are 
doing it, and, thereby, what computing means both epistemologically (that is, in relation to knowing) and ontologically (that is, in relation to being)' (Ali 2016, p. 20). It extends beyond how ideas from postcolonial theory can be used to inform and transform computing fields such as ICT4D, HCI, Interaction Design, and design methods by questioning the historical origins of these domains, past injustices, and the need for reparations as well as their overburdening function within the modern racial world system. Decolonial computing takes the stance of investigating the world from the periphery by being attentive to geopolitical and body political concerns and the persistence of colonial structures (Ali 2014).

We take decolonial computing as our departure point to engage with decolonisation in HCI research. We critically reviewed the literature about decolonisation, both in general and specifically about technology, to argue for the necessity to address some of the risks embedded in the contemporary decolonisation discourse in HCI, such as the potential disregard of epistemologies generated from the periphery as well as of the power-dynamics within communities as a consequence of conceptualising them as homogeneous entities. Further, we drew, synthesized, and built on the perspectives and the work of AfriCHI/ArabHCI authors as well as on the lived experiences of community members to highlight three problematic practical paradoxes - a terminology, an ethical, and a micro-colonisation one that challenge decolonisation thinking. Furthermore, we reflected on our findings and proposed a way forward for researchers and practitioners who wish to adopt decolonisation stances in their work.

As we will show in the article, a decolonisation project is concerned with how researchers, wherever located, might contribute to dismantling and re-envisioning existing power relations, resisting past biases, and balancing Western heavy influences in technology design. We, therefore, need to be vocal and explicit about the political nature of decolonisation. Further, decolonisation, given all the entanglements of globalisation, should be a collaborative labor between researchers in the North and the South.

Overall, this article tries to contribute to some emerging trends and values in the CSCW community which strongly advocate for social justice (Asad and Le Dantec 2015; Bratteteig and Wagner 2016; Chancellor et al. 2019; Dosono and Semaan 2020; Fox et al. 2017; Khovanskaya et al. 2019; Martin et al. 2016). For instance, recent CSCW work focusing on feminist solidarity highlighted the commonalities of challenges and transnational struggles in order to try to establish best practices for sharing lessons across geographies (Kumar et al. 2019). This and similar efforts are in line with AfriCHI and ArabHCI endeavours to create intellectual "humble" spaces to foster mutual inter/cross-cultural learning. Cross-cultural collaborations have become a quasi-necessity as we face globally interconnected challenges. Nonetheless, we believe that global challenges in and of themselves are not sufficient to foster transnational solidarity. Solidarity has to be preceded by must-have difficult conversations about the asymmetry of power relations, and a shared negotiated vision for an imagined new future for all. As CSCW research shows, inter-cultural learning could 
emerge through moments of friction, breakdowns, and gaps (Arawjo et al. 2019). Decolonial thinking, critical thinking, and reflections can all be instrumental in establishing opportunities for mutual learning with the Global HCI and CSCW communities.

Further, we believe that our work could enrich the perspectives of the researchers of the CSCW practice-based community. These researchers are renowned for their orientation towards empirical field studies and ethnomethodological methods as well as the construction of an in-depth understanding of sociomaterial practices (Bjørn et al. 2016). The recent work from this school in Global South contexts leveraged this approach to, among others, critically discuss financial inclusion and mobile money infrastructures (Muralidhar et al. 2019; Ghosh and O'Neill 2020) and engage with the use of ugliness by marginalised groups to invoke dialogues about their controversial traditions (Alshehri and Su 2018). Decolonisation thinking, we argue, could provide an additional analytical lens for understanding sociotechnical practices in the Global South that underscores the role of power structures and local perspectives.

The article is organized as follows. A review of the decolonisation literature is discussed in Section 2. In Section 3, the authors' motivations and background to tackle this research are highlighted, ArabHCI and AfriCHI communities are introduced, and the methods to explore decolonisation as perceived and enacted in both communities are outlined. In Section 4, emerging trends in the communities' views about decolonisation are presented. Three pragmatic decolonisation paradoxes are introduced and discussed in Section 5, while Section 6 provides a summary of contributions. The article is concluded with a proposal to the related research communities in Section 7.

\section{Decolonisation: An Overview}

In recent years, the concept of decolonisation has gone through a significant expansion. Originally coined to describe the socio-political, cultural, and economic processes following the undoing of colonial rule, the interest to decolonise has moved beyond the dismantling of the colonial empires to include many spheres of life. In fact, in recent years the encouragements to 'decolonise' have embraced many fields and included, among others, the necessity to repatriate indigenous land and life (Boveda and Bhattacharya 2019; Tuck and Wayne Yang 2012), critically reflect on existing practices and epistemologies (Ali 2014; Datta 2018; Hajibayova and Buente 2016; Torretta and Reitsma 2019; Zavala 2013), embrace the local processes ( de Martins and de Oliveira 2016; Dourish and Mainwaring 2012; Walters and Simoni 2009), strengthen indigenous theory and practice ( $\mathrm{Du} 2017$; Mawere and van Stam 2015; Nkwo and Orji 2018), and dismantle the colonial status quo (Bidwell 2016; Boveda and Bhattacharya 2019; Keyes et al. 2019; Le Grange 2016).

The following sections highlight the semantic progression that culminates in the domain of technology and technology design, as proven by the emergence of new 
buzzwords in those fields such as decolonial computing, decolonising HCI, and decolonised design.

\subsection{Origin of the Term}

Historically, the term "decolonisation" refers to a temporary or permanent suspension of political, economic, cultural, and/or social domination to (re)transfer national sovereignty rights to indigenous people (Klose 2014). Klose (2014) structured the process of global decolonisation into four phases occurring from 1776 to 1991. The first phase (1776-1826) concerns the series of decolonising waves from European occupations taking place in North and South America. The second phase developed across the world for almost a century (1839-1931) following the dissolution of British colonies in Canada, Australia, New Zealand, and South Africa. The third phase can be associated with the common understanding of 'decolonisation' as it refers to the process of Europe losing control overseas which culminated in the end of colonial rule in 1945. The fourth phase coincides with the collapse of the Soviet Union (1985-1991). For more than 200 years right up to the present, decolonisation still continues to influence the relationship between the European continent and the rest of the world (Klose 2014).

Academically, the term 'decolonisation' was first used by German economist Moritz Julius Bonn in 1932 to refer to the spreading of various decolonisation phenomena in the twentieth century (Klose 2014). Differently from the first two phases, in which a series of revolutionary movements stemmed from increasingly diverging interests between settlers and European metropoles, the third phase saw for the first time the insurgence of resisting forces by non-European populations (Klose 2014). In the aftermath of World War II, "the rapidity of the retreat from modern colonial empire impressed all as it was happening" (Betts 2019, p. 25). Weakened by internal struggles, the 'Great Powers' gradually succumbed to the resistance of the colonies, epitomised by prolonged conflicts such as the First Indochina War (19461954, after which France ultimately withdrew its forces from the former French Indochina) and the Indonesian National Revolution (1946-1954, resulting in the end of Dutch administration over the former East Indies) (Betts 2019; Klose 2014). From the end of World War II, the dissolution of the colonial empires in Asia and Africa was concluded in about three decades (Bonn 1938; Klose 2014), accelerated by the growth of the United Nations - which was joined by 16 African countries in 1960 and by the subsequent adoption of the Declaration on the Granting of Independence to Colonial Countries and Peoples in the same year (Betts 2012).

One of the main motivations for disrupting Western domination stemmed not only from a wish for self-determination but also from a general distrust towards Eurocentric models that conferred little to no importance to local knowledge and value systems. In fact, as a result of the occupation of territories through European colonising enterprises, indigenous knowledge - encompassing a richness of languages, worldviews, and experiences - was hardly acknowledged and systematically 
excluded from European knowledge systems (Battiste 2005; Tuck and Wayne Yang 2012), gradually leading to the strive for an assertion of indigenous values.

\subsection{The Renaissance of Indigenous Values}

The distrust towards the suitability of indigenous knowledge and practices for the challenges of the modern world was not only perpetuated by Eurocentric thinkers but initially replicated by local scholars, too. However, the uncritical application of Western models to local systems soon revealed the potential for 'contradiction and failure' which, in turn, led to 'question the supremacy of European thought' (Battiste 2005, p. 3).

Decolonisation is, therefore, a process stimulated by such a counter-response that sprouts the renaissance of indigenous knowledge, teachings, and tradition by favouring local strategies for development and capacity building (Battiste 2005). Decolonisation also acts as a system of principles that combats the postcolonial legacies undermining decolonial projects by informing any approach that is, by design, aimed at influencing, invalidating, or interfering with the multifaceted representations and cultural richness of indigenous people (Hajibayova and Buente 2016). Self-determination is, therefore, a key component of decolonisation that needs applying to political, cultural, and social domains (Hajibayova and Buente 2016; Ntuli 2002).

The strengthening of an anticolonialist discourse - which finds its foundation in concepts, theories, and disciplines such as oppositional consciousness (Sandoval 2000), critical social theory (Collins 1998), and cross-cultural studies (Mutua and Swadener 2004) - has not spared research-related fields. The establishment of new critical theories focused on self-determination and cultural autonomy has produced greater attention to the relationship between indigenous and Western scholars, highlighting the necessity of 'making Western systems of knowledge the object of critique and inquiry' (Denzin and Lincoln 2008, p. 7). Denzin and Lincoln (2008) clearly outline several criticisms that have been levelled against Western models of research in their endeavours of appropriating and disseminating knowledge about non-Western people. These include: issues of misrepresentation caused by alienating the voices of the supposedly represented ones (Smith 1999); the lack of a localised critical theory which results in the risk of essentialising local actors (Bishop 2005); and the demand that local research is validated through Western standards (Denzin and Lincoln 2008).

\subsection{Decolonised Epistemology}

Following the renaissance of indigenous values and knowledge, decolonisation has inevitably embraced the epistemological discourse, fueled by the emerging contradiction between the influx of socially just Western-funded research and the interests of formerly colonised people (Zavala 2013). The intrinsic issue is that the goodness 
of the intentions embedded in Western approaches and propositions replaces the principle of self-determination (Zavala 2013), with the intrinsic risk of inadvertently resettling Western theories and models (Tuck and Wayne Yang 2012). This contradiction can become more apparent 'at the representational level when the discourse of Western/Modern research that seeks to shed light on the experiences and conditions affecting historically marginalized communities often end up silencing the voices of the researched' (Zavala 2013, p. 66).

Critical commentators have therefore investigated the use of participatory research processes to inform an epistemology that puts indigenous voices at the center of the research process (Datta 2018; Zavala 2013). However, the necessity to reassess power seems to have been addressed less than the issue of how 'participatory' research should be, considering that such voices originate from the same structure that sees a directionality "mostly from the Global North to the Global South, from the "developed" to the "underdeveloped" regions of the world, and from university to community' (Zavala 2013, p. 59). Ultimately, such approaches may inadvertently hide a complete or partial disregard for indigenous agendas and objectives, which may or may not align with Western-originated principles, methods, and ideas (Mutua and Swadener 2004; Tuck and Wayne Yang 2012).

The road towards a decolonised epistemology is, therefore, far from straightforward. According to Tuck and Wayne Yang (2012), a fairer and more representative epistemology is hindered by the superficiality with which the language of decolonisation is adopted in Western contexts. Aware of this and the nonneutrality of current epistemology, we have moved our steps to embrace a polyvocal understanding of decolonisation as the basis from which to discuss and critique the state of affairs of the decolonisation discourse in HCI.

\subsection{Decolonised HCI, Design, and CSCW}

Decolonisation literature has been largely produced with Western scholarship and by Western scholars operating in non-Western contexts. Dominant discourses have been crafted around embracing indigenous worldviews (Bidwell 2016; Hajibayova et al. 2016) while critiquing the blind application of Western epistemologies in nonwestern contexts (Ali 2014; Dourish and Mainwaring 2012; Keyes et al. 2019; Mawere and van Stam 2015). Various approaches have been adopted in the attempt to decolonise existing practices (Ali 2014; Datta 2018; Mawere and van Stam 2015; Tuck and Wayne Yang 2012). The term itself evokes different meanings and uses both from scholars explicitly using the term within their work (Bidwell 2016; Sium et al. 2012) and from those that embrace the practice of decolonisation but choose not to engage with the term itself (Winschiers-Theophilus et al. 2015). Subtle differences in defining decolonisation stem from past experiences, differing worldviews, and positionality. Despite the varied definitions, a common thread can be identified in the need for a paradigmatic shift to recognise the "other" and move away from relying on 
one dominant discourse to shape the trajectory of what we do, especially in multicultural contexts.

The domain of technology and technology design is not exempt from the decolonial project. Ali (2016) posits computing as a colonial phenomenon that requires a critical reflection on its inherent colonial essence. The modern worldsystem is by large modelled after the expansion of European colonisation endeavours resulting in a Eurocentric system with the non-European confined to the periphery. He goes further to state that 'there is no modernity without colonialism', and despite the fact that decolonisation and independence movements around the world have called an end to colonial rule, the remnants of colonialism persist through 'colonial epistemology and ontology' (p. 18). The modern world is being continually transformed through computing. As far as computing is characteristic of a modern world, it is also characteristic of a colonial movement (Ali 2016; Dourish and Mainwaring 2012). Bidwell (2016) suggests that colonial epistemologies are further perpetuated within the HCI domains where African identity has been commonly represented as inferior and underrepresented in HCI conferences, journals, and other outputs.

The work on decolonisation in technology is underpinned by the need to respect and foreground indigenous values and voices. Two dominant attempts to achieve this agenda have been tailored to the work on cross-cultural design/postcolonial computing and decolonial computing. Differences in attempts to address the colonial nature of computing lie in the origin of the call for decolonisation, the extent to which power is negotiated within research teams and design teams, and the nature of participation by indigenous/local people within such teams.

Postcolonial theorists have risen in response to the colonial nature of computing by pushing forward a postcolonial agenda. However, postcolonial theory only addresses one of several possible spheres of colonial computing (Ali 2014). Drawing from its root definition, the term 'postcolonial' relates to the colonial legacy left behind once colonialist structures have been removed. Therefore, post-colonial theory seeks to critically reflect on this colonial legacy, particularly from the perspectives of the colonised. An extension into the computing realm would then see postcolonial computing as an area that seeks to critique colonial practices and elements of power and culture within HCI, ICT4D, HCI4D, technology design, and the broader field of computing. Despite the noble endeavour for critical change, postcolonial computing has its limitations.

A major critique of postcolonial computing is its tendency to address the colonial agenda from an elite worldview, potentially undermining the knowledge that stems from the periphery. Moreover, issues of structural and institutional power are not always explicitly addressed (Ali 2016). This includes work within ICT4D and HCI4D whereby the local reality is viewed as underdeveloped or underserved, therefore it is worthy of being researched upon:

'HCI4D strives to understand users and contexts still little understood, to design and deploy technologies for these users and contexts, and to learn from the 
constraints dictated by low-resource settings and how they are navigated.' (Dell and Kumar 2016, p. 2220).

Despite its noble intentions, such position tacitly implies that the West is the intended audience of the produced knowledge 'about' non-Western contexts, while the latter are the consumers of Western artifacts and technologies. Ali (2016) further states that 'postcolonial theory ultimately constitutes (at least epistemologically) a Eurocentric critique of Eurocentrism' (p. 19), which is self-validating in itself. Hence, the call for a decolonial stance beyond postcolonial thinking.

The decolonial agenda seeks to dismantle epistemological and ontological coloniality (Grosfoguel 2002; Mignolo 2012). This is a shift towards taking a peripheral vantage point rather than from the European core (Ali 2016). Although there are variations within the decolonial stance, it is commonly stated that researchers and designers should be critical of their own stance and be in constant dialogue with those they wish to engage.

However, in the attempt to foreground the periphery, there are multiple cores and sub-peripheries of which to be aware. At the indigenous/local level itself, there is a core and a periphery at play. Therefore, there is a risk that - by promoting indigenous ways of knowing and having technological change come purely from within communities could potentially be treated as homogenous exotic objects, whose traditions and customs should be retained or changed within community power structures. In doing so, those with less power (for example women) within said communities would be denied the opportunity to engage with technological endeavours that have an empowering agenda. In light of the above, decolonial computing calls for a shift in thinking by encouraging us to pay more attention to 'body politics' and 'geo-politics' (Ali 2016, p. 19), namely to reflect on whose knowledge and origins a paradigm is consistent to. Hence, only when foregrounding the periphery is paired with a critical reflection in relation to the Who and Where of computing the issues of power can be addressed (Torretta and Reitsma 2019). Torretta and Reitsma (2019) suggest that the positionality of researchers is always evolving and hence the need for continuous critical reflection on one's position and how it influences their work. This is in line with recent calls on HCI scholars to acknowledge and reflect on personal positions and biases (Ogbonnaya-Ogburu et al. 2020; Schlesinger et al. 2017).

Moreover, a decolonial stance further attempts to move beyond issues of culture, coloniality, and power to spheres where race and reparations are not overlooked. We are therefore not only concerned about what we will do with computing going forward, but also to reflect and act on the current impact of computing from past endeavours.

Post-colonial (prevailing in ICTD and HCI4D communities) and decolonial stances share a genuine interest in foregrounding the challenges of designing and using computing technologies at the periphery. That, arguably, makes it difficult to draw a rigid line between them considering that researchers' stances might evolve or 
change due to pragmatic reasons (e.g., funders or community requests), and that some might deter from the explicit use of the decolonisation term as we discuss later. Nonetheless, we believe that the following overlapping issues distinguish decolonial stances from the post-colonial, ICTD, and HCI4D ones.

There are excellent examples of ICTD/HCI4D research that have critically foregrounded the challenges and nuances of the local users at the periphery by examining its impact in unmarked local contexts (Ahmed et al. 2020; Morshed et al. 2017), its applications in domains such as education and learning (Uchidiuno et al. 2018; Varanasi et al. 2020), as well as reflecting on the use of Western design methods in these contexts (Wyche 2020). The majority of these works, however, still represents the locals as the researched-at-the-margins to which Western methods are applied and where power might be unbalanced in favour of the researchers. Conversely, researchers leaning towards decolonial stances strive to foreground the issues at the margin by repositioning the margins at the center, thus adopting approaches attentive to power dynamics and power-sharing with the locals. As put by Smith (1999), the commitment to decolonial stances changes the landscape of the research:

'When Indigenous peoples become the researchers and not merely the researched, the activity of research is transformed. Questions are framed differently, priorities are ranked differently, problems are defined differently, and people participate on different terms.' (p. 193).

Consequently, community partnership, bottom-up approaches (Kapuire et al. 2015; Rey-Moreno et al. 2013; Therias et al. 2015; Winschiers-Theophilus et al. 2010), and the focus on the indigenous knowledge and philosophies are more salient (de Martins and de Oliveira 2016; Reitsma et al. 2019; Winschiers-Theophilus and Bidwell 2013). Further, decolonial stances are more vocal concerning the extent to which researchers critically reflect on biases and issues of power, while challenging the dominance of Western methods (Giglitto et al. 2018; Nassir and Leong 2017; Smith et al. 2020; Yoo et al. 2018).

Overall, various scholars have proposed three practical strategies for adopting a decolonial stance:

1. Advocating for indigenous worldviews

Designers, researchers, and advocates of the various fields of computing should at the very least acknowledge and reflect on their origins, ways of knowing, and being (Ali 2016). There is a need to redefine collaboration, ownership, relationship building, and embracing indigenous worldviews (Cochran et al. 2008; Datta 2018; Walters and Simoni 2009). This may require understanding anti-racist theories and practice (Datta 2018). More importantly, in cases where indigenous communities have experienced negative effects of technologies and where computing has been seen to constrain local traditions, there is a continued need for researchers and designers to be cognisant and critical of the implications of their work (Du 2017). 


\section{Re-calibrating power relationships}

This means taking on an ethical imperative and being reflective in advancing computing from the perspective of those at the peripheries of the current world system, namely to decentre existing power relationships and embrace frontier epistemologies (Ali 2016). Several researchers have approached this from the perspective of using technology to promote the local including the preservation of cultural heritage while influencing the decolonisation agenda (Cochran et al. 2008; Tamarkin 2011). Case studies such as the use of DNA technology to scientifically substantiate ethnic communities (Tamarkin 2011) and the use of technology for preserving indigenous knowledge (Giglitto et al. 2018) are cases in point.

3. Adapting to and integrating local systems

Adaptability, respect and sensitivity towards the local context and local culture are beneficial for developing a cooperative relationship between researchers and local communities (Winschiers-Theophilus et al. 2015). This may require further reflection on how local views are constituted. Moreover, such a perspective develops a needed countermeasure against colonial practices that threaten indigenous ways of being (Sium et al. 2012).

Explicit efforts to stimulate local capacity building and engage in decolonial practices are increasing. For instance, Giglitto et al. (2018) critically engage with the $\mathrm{CHI}$ community and challenge $\mathrm{HCI}$ researchers to investigate power and diversity in both local and global contexts amid cross-cultural design. Nkwo (2019) examines persuasive techniques employed by indigenous traders in conventional African marketplaces to uncover the design requirements that could be operationalised on an eCommerce platform. Berzowska et al. (2019) propose to develop tools to support the understanding of the materiality of HCI drawing from various lenses, including indigenous knowledge. Mawere and van Stam (2019) advocate for alternative information society architectures that align with local epistemologies and encourage participation and inclusion of African communities where the African voice is part and parcel of digital progress.

Parallel to these efforts, two scholarly CHI communities, AfriCHI and ArabHCI, have paved the way for investigating the issues of decoloniality and postcolonial computing from the periphery and for advancing the fields of $\mathrm{HCI}, \mathrm{CSCW}$, and practice-based $\mathrm{CSCW}$ research beyond the dominant discourses. We will discuss both communities in the next section.

\section{Engaging from the Periphery}

\subsection{Authors' Background and Values}

This article presents our insider-outsider perspectives of the challenges and paradoxes in decolonising $\mathrm{HCI} / \mathrm{CSCW}$. As an international team from diverse 
backgrounds, our lived experiences and research engagements culminate in the views put forward in this article.

- The first author is an Egyptian Associate Professor of Computer Science at the City of Scientific Research and Technology Applications, Egypt, and the cofounder of ArabHCI;

- The second author is an Italian HCI and Cultural Heritage postdoctoral researcher at Sheffield Hallam University, UK;

- The third author is a Nigerian HCI PhD student in the Department of Computer Science of Ebonyi State University Abakaliki, Nigeria;

- The fourth author is a Namibian researcher at the University of Namibia, Namibia;

- The fifth is a Namibian Computer Science master's student at the Namibia University of Science and Technology, Namibia;

- The sixth author is the pro-vice chancellor for Research, Innovation and Development at the University of Namibia, and the founder of AfriCHI.

Our unique encounters and cross-cultural engagements motivated the need to amplify the voice of non-Western researchers in relation to technology design and research. We have all engaged in a number of activities (conferences, workshops, summer schools) led by the AfriCHI and the ArabHCI communities and have been challenged to start thinking differently about how we approach our work and the way in which to reflect on decolonisation.

Since the first AfriCHI conference in 2016, the first author has focused her efforts on research collaborations between the Global North and the Global South and how these could be "decolonised". Much like the first author, the subsequent authors have been challenged by their experiences and cross-cultural learning to reflect and act on indigenous ways of knowing and being within their research:

- The sixth author has actively taken a stand to address the underrepresentations of Africans as $\mathrm{HCI}$ researchers and practitioners through the establishment of the AfriCHI conference series in 2016. Her drive to foster African HCI scholarship stems from her first-hand experience of indigenous people in Namibia taking a stand against colonisation (given the brutal colonial past including the genocide of indigenous people). Similarly, the fifth author has been inspired by the sixth author to confront the challenges of decolonisation and the under-representations of African HCI scholars.

- The second author's first engagement in a transnational project (involving countries both from the Global North and the Global South) prompted him to reflect on how Western HCI methods could be indigenised and designed to effectively tackle cross-cultural challenges.

- The third author's work has focused on designing culturally appropriate technology interventions. His aim is to allow indigenous people to claim back power through community participation during conceptualisation, design and implementation of technology systems. 
- The fourth author has been prompted to reflect on how knowledge should be shared across cultures and contexts in mutually beneficial ways. This emanated from her concerns about whose voices dominate and whose are under-valued within the ICT4D space.

Although we strongly believe in the need to ensure that the voices of indigenous people are properly captured in the design of technology-mediated interventions, it is important to note, however, that we do not preemptively reject Western approaches to technology design. Rather, we design with communities based on their context, knowledge, resources, requirements, and aspirations whilst choosing to use or adapt Western approaches and principles as the phenomenon under study and context might suggest.

We believe that this article will - among other things - explain the need for open discussions regarding the choices and the approaches to be employed in research (including the collaborations and partnerships that ensue) across the Global North and South, and offer a variety of perspectives to address existing issues in decolonising HCI studies. In addition, we hope that this article will present our perspectives as indigenous and non-indigenous researchers and encourage deeper collaborations in $\mathrm{HCI} / \mathrm{CSCW}$ and decolonisation studies amongst researchers across borders.

\subsection{AfriCHI and ArabHCI Scholarly Communities}

In order to define 'decolonisation' as well as understand its impact and objectives in reference to indigenous endeavours, we have sought the collaboration of people affiliated with AfriCHI and ArabHCI communities dealing with, among others, issues of decolonial and postcolonial HCI.

\subsubsection{Origins and Focus}

ArabHCI and AfriCHI are grassroots initiatives that evolved organically to enable researchers of both communities to self-represent and take pride in their cultures. Both communities recognise the heavy influences originating from the Western HCI discourse, while asserting the need to counteract such domination in HCI projects with/for African and Arab users.

AfriCHI was based on the perceived necessity of asserting the validity of a potentially different way of working of African researchers. According to Bidwell (2016), this would put them at a disadvantageous position in the mainstream HCI discourse as their cultural practices may not align with the expectations of Western structures such as strict deadlines, rigid word limits, slides, and paper layouts. The attempt to provide African researchers with a space that enables them to undertake research and dissemination practices that are different from the Western counterparts led to the creation of the biannual African Conference of Human-Computer Interaction that was held in Kenya and Namibia in 2016 and 2018, respectively. The 
conference adopted culturally-sensitive forms of presentations such as encouraging oral and multimedia expressions, providing local languages interpreters in some workshops, enabling community elders to present their own design work, observing the culturally appropriate protocols for conference openings and closings, hosting panel discussions in circles to avoid the expert-audience distinction, and allowing participants equal opportunities to talk. The conference also explored what innovation and design mean to the African researcher and audience.

Similarly, one of the premises for establishing ArabHCI was an effort to counterbalance the tendency of using Arabs as case studies for Western researchers in Araboriginated (but of global significance) events such as the Arab Spring and the refugee crisis (Alabdulqader et al. 2017). Focusing on the HCI domain, ArabHCI sides with AfriCHI with regard to the fact that intellectual efforts for advancing $\mathrm{HCI}$ should come from localised efforts (Alabdulqader et al. 2017). As stated by Lazem et al. (2019):

'One of the main motivations for creating the ArabHCI community was the superficial representation of the socioeconomic and political nuances of the region in the research that addressed the Arab Spring and Arab refugees. Indeed, we felt that an insider understanding of the context was not fully leveraged. [...] The misrepresentation of Arabs was frustrating for many Arab researchers, especially with the rise of Islamophobia, and accordingly was dominating some of the community's early discussions. One of the submissions we received to our workshop at DIS 2017 was titled "Arabs Are Not Refugees Nor Terrorists" the point being, there is more to the region than such stereotypes.' (p. 42).

AfriCHI and ArabHCI present several other similarities in their respective approaches. For instance, building the capacity of local designers and HCI researchers is key to both communities, as shown by the clear attempts of catalysing an Afrocentric HCI curriculum (Lazem and Dray 2018), promoting HCI research in Arab countries (Alabdulqader et al. 2017), and holding regional HCI educational events (Peters et al. 2019). The development of local researchers - who are supposedly more knowledgeable of and likely to be more sensitive to power and contextspecific issues - could be seen as an attempt to develop decolonised curricula and pedagogical approaches committed to addressing that lack of HCI resources that voices the concerns of the members of both communities.

Building collaborations with Western and local researchers is central to the agenda of both communities, as it was manifested in the theme of the first AfriCHI conference, 'Building Bridges, Breaking Barriers', and expressed in their objective to 'Promote collaboration, dialoging and networking opportunities in $\mathrm{HCI}$ between International and African scholars, researchers, students, practitioners, and teachers across the sectors'. By the same token, the calls for participation in ArabHCI activities explicitly welcome non-Arab researchers who are interested in research in Arab contexts. As stated on their website, one of the main goals is to 'Facilitate 
collaboration with well-established international HCI research labs in academia and industry". Both AfriCHI and ArabHCI are eager to collaborate with the international community, but on equal grounds, where insider or local perspectives are not disadvantaged:

'Using the lens of intersectionality, ArabHCI therefore strives to demonstrate the intracategorical complexity of "Arabs" in HCI research [...] and encourage Arab and non-Arab researchers to be open and self-reflective on their own biases' (Lazem et al. 2019, p. 42).

Both communities actively organise and run intellectual spaces, workshops, and conferences as humble participatory mediums for local researchers, where ideas and collaborations are nourished, negotiated, and fostered, and where local representations and knowledge are advantaged (Bidwell 2016). Overall, the decolonising tendencies conceptualised and embraced by AfriCHI and ArabHCI communities are about why and how to bring marginalised local voices forward in technology design.

\subsubsection{Stances}

A systematic review of the related literature produced by these communities shows that the term "decolonisation" is not explicitly employed to describe the stances adopted by researchers in these communities. However, we were able to map this literature to the three partially distinct practical decolonisation strategies discussed in Section 2.4. By mapping some of this literature to their corresponding decolonisation strategies, we show the implicitly adopted decolonial stances.

Firstly, efforts have increasingly been produced to recognize and appreciate their origins, values, and indigenous ways of knowing and being (Alabdulqader et al. 2018, 2019; Awori et al. 2016a; Jordan et al. 2016; Lazem and Dray 2018; Lazem 2019; Lazem et al. 2019; Warrick et al. 2016). Furthermore, these studies very often aim to uncover local knowledge and perspectives, patterns, and thoughts that could be used to solve local problems (Abokhodair et al. 2016, 2017; Al-Dawood et al. 2017; Awori et al. 2016b; Gallert et al. 2016; Winschiers-Theophilus and Bidwell 2013; Peters et al. 2016; Taylor et al. 2016; Walton et al. 2016). We mapped this literature to the advocating for indigenous worldviews strategy.

Secondly, AfriCHI and ArabHCI researchers also take on principled stands which are crucial in navigating through existing issues of power dynamics as a means to promote indigenous knowledge (Adamu 2016; Bayor et al. 2018; Itenge and Winschiers-Theophilus 2018; Hamidi et al. 2018; Kauhondamwa et al. 2018; Molapo et al. 2016; Ssozi-Mugurura et al. 2016). We mapped this literature to recalibrating the power relationships strategy.

Thirdly, our review of AfriCHI and ArabHCI literature revealed that researchers might become more flexible, respectful, and sensitive to the social context and culture of the local communities where the research is being carried 
out. In fact, a wealth of literature suggests the presence of a considerable amount of responsiveness to the cultural, socioeconomic, and political nuances of their respective regions (Amukugo and Peters 2016; Awori et al. 2016a; Belay et al. 2016; Gallert et al. 2016; Ghaznavi et al. 2016; Jere et al. 2016; Kawu et al. 2018; Katusiime and Pinkwart 2016; Lazem and Jad 2017; Mahmoud et al. 2018; Mgala et al. 2016; Molapo et al. 2016; Namara et al. 2018; Nassir and Leong 2017; Nkwo et al. 2018; Oguamanam and Gansallo 2016; Saleh and Sturm 2018; Saleh et al. 2019; Smith et al. 2016; Ssozi-Mugurura et al. 2016). We mapped this literature to the adaptation to and integration of local systems strategy for adopting a decolonial stance.

\subsection{Methodology}

We build on personal cross-cultural work, lived experiences, our engagement with the ArabHCI/AfriCHI communities, and critical interpretation of the decolonisation literature to frame the challenges local researchers face as they adopt decolonisation stances to generate three problematic and interrelated paradoxes, which we will discuss in Section 5. In framing the paradoxes, we use a decolonial computing lens (Ali 2016) to give visibility to the body politics of those involved in the research conducted in non-Western contexts. Further, we examine the geopolitics of research as we interrogate the origin and the destination (to whom) of the research agenda, methods, and knowledge. In doing so, we unearth the tensions local researchers face as they pursue decolonisation practices. Masking or ignoring these challenges put local researchers at the risk of perpetuating/reproducing colonial attitudes, while underscoring them might jeopardize their chances of collaborating with or being recognised by Western scholars. Hence, we framed them as paradoxes.

Further, we sought to gain a glimpse into the local researchers' perspectives on the issue of decolonisation. We aimed to complement these perspectives with our study of the literature and our personal experiences, and to investigate their alignment or lack thereof with the proposed paradoxes. Particularly, we were interested in exploring answers to the following questions:

- Are the issues related to decolonisation perceived among the top priorities of both communities? The purpose of this question was to obtain an updated outlook of the communities' perspectives on their stances since their inception in 2016.

- What is the extent to which AfriCHI and ArabHCI community members are engaged with the term "decolonisation" in their research? This question aimed at probing a gap that we observed throughout our own work and discussions of the reviewed literature. That is, the adoption of decolonisation tendencies is not necessarily accompanied by the use of the term. Realizing that the term carries a heavy baggage from the past, for some regions and countries more than others, we wanted to explore the engagement with the term by both communities. 
We distributed an online anonymised survey to the 2016 and 2018 AfriCHI committee members as well as to the organisers of ArabHCI events since 2016. Though we initially wanted to apply a participatory approach to this research, the sensitivity of the topic was one of the main factors for choosing the anonymised survey method as we wanted to provide a safe space for our participants within which to provide their views. We informed our participants that their responses would be analysed to be included in an academic output. It is worth noting that our interpretation of the participants' responses is inherently restricted by our limited understanding of their context. The method is also limited in the sense that we did not engage the participants to review and discuss our interpretations. The survey was sent by email, followed by personalised messages inviting them to respond. We noted that 12 out of the 17 responses from AfriCHI committee members were given only after they received an individual message from a familiar person within AfriCHI who shared the importance of their voice being included in an academic output. The inclination to not respond to surveys might be observed as being common across different communities, but it might have a specific meaning within AfriCHI as committee members would not voice opinions in meetings, group emails or chats, but rather expressed these in one-to-one chats and emails when trust was established.

In the survey, participants were asked to describe the top three objectives of their local HCI community as well as their reasons for joining. They were asked to indicate whether or not they had heard the term decolonisation. In case of a positive response, they were asked to define it, and indicate and justify whether or not decolonisation lessons are important for their research and the community. If they reported not knowing about the term, they were instead asked to indicate whether putting an emphasis on local knowledge, rather than relying on Western knowledge and influences, is important to their research and the community. A total of 20 respondents, consisting of 17 out of 45 recruited people from AfriCHI and 3 out of 6 from ArabHCI, responded to the survey.

The responses were analysed using content analysis to elicit answers to the abovementioned questions and identify any pertinent themes.

\section{Communities' Views on Decolonisation}

In this section, we summarise the views on decolonisation of people affiliated with AfriCHI and ArabHCI. According to the respondents, the top aims of AfriCHI and ArabHCI communities are building local HCI scholarship, including raising awareness and promoting HCI scholarship, increasing the visibility of local researchers, and building a local scholarly community as a platform for local researchers. Aspects of decolonisation have emerged from the perspective of designing solutions that are more inclusive to the local voices in light of 'telling the story as it is', seeking 'epistemic justice', or 'rethinking the design, evaluation, implementation of 
interactive systems from the African perspectives. These responses implicitly demonstrated that decolonisation is at the core of the discussions within both communities.

With respect to a definition of decolonisation, 19 participants (out of 20) indicated their familiarity with the term. Very few respondents viewed it from a purely political stance in terms of freedom, liberation, and independence from a coloniser. The majority of participants referred to decolonisation efforts in the present tense as an ongoing continuous effort to lift the heavyweight legacy of the colonisation period through a shift in the way of thinking of and altering the status quo. Decolonisation is seen as a change in mindsets to embrace the idea that locals 'can do it' bymeans of disconnecting from and questioning Western thoughts in favour of indigenous ways of thinking. In other words, accounting for the local rather than undermining it.

We encountered three recurring themes in the answers. The first relates to decolonisation in relation to global $\mathrm{HCI}$, framing it as a device to counteract colonial legacies in the global HCI discourse. The second theme was concerned with asserting the local identity, while the third saw decolonisation as a method/device to ensure that local voices and context are central in technology design.

The themes confirmed our initial intuition that decolonisation is a 'living' term in both communities, which was additionally evidenced to be a 'living' practice in the communities' research (as shown in Section 3.2). The survey responses and the literature have substantiated the need to outline the challenges faced by local researchers as they use decolonisation terminology and/or conduct decolonising work.

\section{Practical Paradoxes of Decolonisation in HCI}

Using decolonial computing as a reflective lens on our own experiences as well as the perspectives gathered from existing works, this article proposes three problematic and interrelated practical paradoxes that challenge the proper establishment of decolonisation $\mathrm{HCI} / \mathrm{CSCW}$ practices for local researchers. The terminology paradox interrogates the origins of the term and problematises its use by local scholars in Western-dominated knowledge systems. The ethical paradox draws attention to the power dynamics involving local researchers in joint collaboration with Western scholars. The micro-colonisation paradox foregrounds the rather awkward insideroutsider position of the local researchers with respect to their communities. The three paradoxes represent the view from the periphery. Next, we will discuss the AfriCHI and ArabHCI communities' responses to the survey in relation to these paradoxes.

\subsection{The Terminology Paradox}

The terminology paradox relates to how local researchers identify with the term "decolonisation" and its potential politicising effect as they express their views on indigenous knowledge and relations with the West. The paradox comes down to 
whether or not local researchers' should be explicit about their decolonisation stance. Some authors are precise about their decolonisation stances (Awori et al. 2016a; Bidwell 2016), but as this is not a universal proclivity among the scholars from the ArabHCI and AfriCHI communities, this paradox assumes a significance worth discussing.

The absence of the political stances taken by researchers is criticised within global HCI scholarship as stated by Keyes et al. (2019): 'Allowing our political stances to remain unspoken has constrained our ability to question and challenge the consequences of the work we put into the world' (p. 2). This issue might be amplified in relation to unspoken decolonisation stances due to the fact that the term could be defined along different lines. In fact, the term "decolonisation" could elicit different responses depending on the adopted worldviews. Local researchers might be grappling with the term itself and rather playing it safe by using other words that do not evoke a particular image that might accuse Western researchers of pursuing colonising practices.

This impasse encouraged us to reflect on the appropriateness of embracing a plain use of the term in research and publications. Particularly, we pose two questions about who should talk about decolonisation and what we might miss by choosing not to use the term. To answer the first question, a follow-up question naturally emerges, that is whether decolonisation is an issue that only concerns the formerly colonised. We disagree with this proposition as most decolonisation projects are grounded in the effort to revoke injustice and re-create a different reality, a better world. It is true, however, that the Western discourse about decolonisation is lacking in representing local voices, and that most of the literature can be retrieved from a Westernoriginated discourse. This might deter local researchers from engaging with the term, as one respondent put: 'I think that if the [decolonisation] lessons are given by the right people, Africans to be specific (in the context of AfriCHI), it will be essential for my work, because we somehow still operate in a colonised way'. Furthermore, asking local researchers to be explicit about decolonisation might necessitate the existence of resistance strategies and practices, and, in the absence of proper local resources or local interest to initiate decolonisation projects, the probability of such strategies and practices to be conceptualised within the realm of "all talk and no action" (in comparison to Western researchers that thanks to their resources can take action and provide solutions) seems rather high. Furthermore, using trending words that convey certain perspectives (e.g., ICT4D or postcolonial computing) might ensure a higher probability of their work being found or accepted by particular international publication venues.

In terms of what might be missed by not using the term, we argue that it would push local researchers to operate within Western-originated frameworks such as ICT4D or postcolonial theory and, therefore, raise their concerns in reference to positions other than their own. Conversely, using the term could encourage local researchers to vocally discuss decolonisation issues, i.e. reflecting on the 
body politics and the geopolitics when working with local communities, within frames that are fully supportive of such discussions.

The data supporting our discussion around the local researchers' struggle with the decolonisation terminology resulted from contrasting the answers to the questions about the significance of the decolonisation term to the respondents' work with the answers given to questions where the term decolonisation was replaced with one possible definition of it, namely 'putting emphasis on local knowledge, rather than relying on Western knowledge and influences'. The survey was originally designed so that the respondents had to answer only one set of branching questions depending on whether they were aware of the term or not. However, the survey unintentionally allowed them to access and answer both branches of questions. We were surprised to notice a slight difference in the tone of the answers to what were, from our point of view, similarly framed questions.

We observed that some respondents expressed different perspectives when the phrasing 'local knowledge' was used compared to using the word 'decolonisation'. Those views were not contradictory but rather voiced slightly different concerns. Specifically, three patterns were noticed. The first pattern is composed of those who thought decolonisation was important to be aware of but not necessarily to act upon, as summarised by the following quotation:

'I don't think the decolonisation lens itself should be imposed on all research done in Africa, but I think it is an important lens to be aware of and very necessary in a southern african context. I also think that many computer scientists, including African computer scientists would rather (wrongly) believe that science is neutral.'.

When asked about placing 'emphasis on local knowledge' (the second set of branching questions), the same participant, however, emphasised that action should be taken in relation to putting an emphasis on local knowledge rather than relying on Western knowledge and influences, '[...] because it is hard research and needs support, even if not everyone is asking those questions.'

In the second pattern, the respondents thought decolonisation matters, as summarised by the following quotation: 'the remnants of colonialism in institutional practices and individuals behaviour still have consequences'; however, when asked about local knowledge, they raised the concern that local knowledge is not sufficient by itself and it should be complementary to Western knowledge: 'Yes, given the history of focus on Western knowledge, there is certainly an argument for foregrounding local knowledge now. However, I believe those (sic) knowledge bases should be considered complementary rather than adversarial'. This view is similar to Datta (2018), who adds that Western knowledge should adapt to the local context such that local researchers can learn from indigenous knowledge without entirely rejecting all Western methods and theories. 
In the third pattern, the respondents believed that both concepts are important for the community for different reasons: decolonisation mattered so that the lessons from history could help shape a better future, while local knowledge mattered because it represents the right way to solve local problems.

While the observed patterns are limited by the small number of survey responses, they are indicative of the need to further unpack the adoption of the decolonisation term by local and Western researchers. Decolonisation as a concept is not owned by the periphery. Rather, the periphery had to engage with it because it has become a legitimate way, from the Western perspective, to talk about certain types of technology-mediated endeavours. One may wonder whether an alternative concept or term that is owned by the periphery could emerge when the periphery becomes the central actor, rather than the central subject, of decolonisation research.

\subsection{The Ethical Paradox}

The ethical paradox is concerned with the consequences of the spatial bifurcation of knowledge into the center (Western knowledge) and the periphery (local knowledge). From the perspective of local researchers, central to this paradox is the question of the moral correctness to pursue decolonisation endeavors via Western projects, systems of knowledge, and agendas. Some authors have raised concerns towards the application of Western resources and methods, highlighting in the process a variety of potential issues such as the lack of familiarity with the context of intervention (Alabdulqader et al. 2019), the proposition of one-size-fits-all solutions (Saleh et al. 2019), and the negligible consideration of local social norms (Jere et al. 2016).

Despite the good intentions of many international projects, inherited power inequality is usually embedded in how, for instance, funds are structured, and oftentimes the voices of the local researchers and their communities might fall between the cracks. Previous research carried out by two of the authors in an internationally funded project to design mobile applications to preserve the Egyptian Bedouins intangible heritage (e.g., songs, poems, oral traditions, etc.) confirmed the necessity of exploring these aspects (Giglitto et al. 2018). The project employed a participatory design process aimed at empowering the local designers and the local community. A special exercise was designed to unpack the local designers' perception of power dynamics between the Bedouin community, the international funders, and the academics involved. An underlying colonialist flavour was observed as local designers indicated that the funders and/or the academics possessed the most power in the project and gained the most benefit. Local designers could still picture a lack of agency compared to other international stakeholders regardless of the efforts to give them the lead. Consistently with decolonial thinking, we thus argue that crosscultural teams should find ways to inspect, balance, and reflect on the power inside the team, and be explicit about the ultimate beneficiaries from the produced work. 
The partnership and collaboration with Western researchers could be also motivated by local researchers preferring to invest in building ties with established researchers from the West as a way of making progress in the field. Although this might be a valuable strategy to better disseminate one's work, the risk is to neglect local researchers' views and potentially replicate the limited narrative that one's work is only good if it follows Western worldviews or it is associated with wellestablished Western researchers.

The power inequality in the global CSCW/HCI scholarship creates challenges for local researchers to disseminate in Western venues the knowledge generated in local contexts; a process that is essential for their academic progress. Most Western reviewers make use of their knowledge, experiences, attitudes, values, and norms to validate the work from indigenous researchers (Bidwell 2016). This contributes to the ethical paradox that sees local knowledge, valued by local researchers, in reality undermined, devalued, and omitted in order to conform to the reviewers' worldview, further perpetuating the behaviour that assumes 'real knowledge producers' to be in the Global North, with the South seen as 'deliverers of information' (Buskens and van Reisen 2017; Mawere and Awuah-Nyamekye 2015). The paradox goes further when knowledge outcomes are kept from local researchers and institutions behind Western publishers' paywalls (Mawere and van Stam 2019).

The bifurcation between Western and local knowledge was found in the responses of the 16 participants who chose to answer the questions about local knowledge in the survey. Overall, the respondents saw innovation as generated through diversity and hence the need to acknowledge both local and Western knowledge, echoing Mawere and Awuah-Nyamekye (2015) who stated the need to move towards a more inclusive narrative that embraces diversity and recognises indigenous ways of knowing. Context should then be the guide to what would work best in a given circumstance.

The dominance of Western knowledge and the wish for a more balanced grounds for collaboration were evident in the participants' responses. Local knowledge was pragmatically seen as complementary to the 'advanced' Western knowledge rather than an alternative, as shown by the following quotations:

'Western knowledge is advanced no doubt, we should add it to what we know to become better people.'

'[...] We have not gotten to that point where we don't need Western knowledge. Western knowledge should be complementary to our local knowledge.'

'[...] we can learn from Western knowledge (we don't need to reinvent the wheel for something that is common)'.

In terms of the practical ways in which Western knowledge could be incorporated, respondents proposed to use it to inspire local researchers ('The focus should be on 
inspiring from rather than copying the Western knowledge'), to adapt it to the local context ('[...] how we apply such knowledge has to consider locality'), to apply it on selected problems ("[...] Application of Western knowledge should be used where relevant, and for contextual problems that "Western knowledge" cannot explain, new knowledge must be developed'), and by embracing a more inclusive view ('Yes, again due to the historical focus on Western knowledge that has dominated up to now. However, there are constructive, inclusive ways of doing that').

Decolonial thinking encourages local and Western researchers to reflect on the implications of knowledge bifurcation, the alignment of interests versus the alignment of values in Western-local collaborations, and the power structures in these partnerships (similarly to Giglitto et al. 2018). In fact, some collaboration practices might use the partnership to promote one way of being and doing. It is however important to note that building and maintaining partnerships and addressing issues of equitability is not an easy task as the direction of the flow of money often plays a role in the distribution of power during the decision-making process (Carbonnier and Kontinen 2014).

\subsection{The Micro-Colonisation Paradox}

The micro-colonisation paradox addresses the temporal contrast between pre- and post-colonial eras. It relates to the fact that some local researchers perceive decolonisation as belonging to the past, and believe that a globalised worldview, which is unavoidably dominated by Western discourses, is the way forward. The trouble with this position lies in the fact that a globalised worldview is universal rather than pluriversal and hence is not reflective of local realities. Adopting a globalised worldview might lead to local research endeavours that blindly use methodologies and epistemologies in which indigenous ways of working might be overlooked or diminished at best (Nassir and Leong 2017) or colonial legacies might be inadvertently reproduced locally at worst (Giglitto et al. 2018; Mawere and van Stam 2015). We call this phenomenon micro-colonisation. Following, we use our reading of the decolonisation literature to engage with the respondents' views pertaining to this paradox and supplement the discussion by a direct experience of two of the authors.

Some respondents raised doubts about the importance of decolonisation lessons to their research and communities. A decolonisation stance was positioned as clinging to a remote past, as opposed to being part of a current globalised interconnected world. As one participant put it, 'the world has become interconnected and so it is important to see research as a bridging endeavour between cultures.' Other participants used expressions such as 'dwelling on the past' and 'it is always good to know history'. One participant went further to say: 'I don't think the decolonisation lens itself should be imposed on all research done in Africa". Respondents agreed, however, that it should not be totally ignored: 'A mix of how our ways of life impact 
technology design in relation to the broader world should guide how AfriCHI moves forward'; '[...] It's true that it should be discussed but not too much'.

This view is consistent with the work of postcolonial scholars such as Philip et al. (2012), who state the necessity 'to move forward together, rather than remaining mired in regretful contemplation of past biases' (p. 3). However, this view has been criticised by decolonial scholars such as Ali (2014), who lamented postcolonial computing scholars' silence about issues of reparations, suggesting that such a position is ethically suspect as it presents postcolonial researchers as beneficiaries of the asymmetric power relations, which, he argues, means the persistence of past biases: "past biases" are not located only in the past, but persist in the present and into the foreseeable future, reproduced by structures and the agencies, both human and non-human, embedded within them' (p. 3).

Though Dourish and Mainwaring (2012) rightly acknowledge that questioning technologies for tomorrow 'blinds us to the questions of our ongoing responsibilities for what we built yesterday' (p. 6), Ali (2014) suggests that a decolonial perspective requires the interrogation of the body politics and geopolitics of the pronouns 'we' and 'us'. We postulate that such interrogation becomes even more important if those 'we' and 'us' include Western and local researchers. Phrases such as 'good to know history' and 'dwelling on the past' might hide the notion that current local research is free from colonising practices and, therefore, well suited to the local context.

The irrelevance of decolonisation to the 'universal' knowledge discourse was manifested by another respondent who expressed that decolonisation does not matter based on the belief that the knowledge about the way artificial intelligence (AI) works is independent from the context: 'I am doing research on AI which is the same everywhere'. An issue that is worth unpacking relates to the perpetuation of the Western belief in the universality of science or that '[...] knowledge schemes developed anywhere will work just as well anywhere else' (Dourish and Mainwaring 2012, p. 2). The neutrality of AI research in the Global South has been recently questioned by HCI scholars, who have drawn attention to implicit Western assumptions and beliefs that might be normalized in global AI systems (Sambasivan and Holbrook 2019). For instance, Internet data used to train AI models is skewed towards Western content, which could lead to biased recommendations for user groups (e.g., indigenous communities) whose mother languages are less represented on the Internet. Further, AI systems used to personalise Internet content assume that individual private use of devices is the norm, which is not true for many women in the Global South (Sambasivan and Holbrook 2019).

The fact that the micro-colonisation trap might not spare indigenous researchers makes it potentially omnipresent in cross-cultural design processes. Evidence suggests how local designers trying to engage with a culturally distant community can develop attitudes that are considered by postcolonialism theory as typical of the imbalanced power relationship between Western and local researchers, such as a lack of empathy, disregard for cultural specificities, and tendency to adopt "othering" perspectives (Giglitto et al. 2018). 
The lessons from the micro-colonisation paradox not only assert the continued need to openly reflect on present and past practices by local researchers, but also that reflections, awareness, and discussions should probably be followed by a reevaluation of the methods local researchers use in local contexts. We, therefore, argue that adopting a decolonisation perspective that is being explicit and vocal about the need to accommodate pluriversal voices is an opportunity to scrutinise and problematise local-to-local practices, particularly the positions of local researchers in cross-cultural teams.

\section{Summary of Contributions and Significance for HCI/CSCW}

In this article, we have discussed three interrelated paradoxes associated with decolonisation - defined as terminology, ethical, and micro-colonisation paradoxes that were generated from our lived experiences, the literature, and the survey responses. One of the questions we left unanswered was how to bring marginalized voices forward in technology design since methods were not the primary focus of the article.

The contributions of this article can be summarised in three main points. Firstly, we argued that the postcolonial stances in $\mathrm{HCI} / \mathrm{CSCW}$ - albeit promoting a sensitisation towards cultural and contextual specificities - neutralise rather than problematising questions of power dynamics, leaving them uncovered at worst and unreflected upon at best. Politically neutral post-colonial stances in $\mathrm{HCI} / \mathrm{CSCW}$ carry the risks of unknowingly perpetuating a colonised worldview where local epistemologies are disadvantaged. We, therefore, establish the need of considering decolonial thinking lenses to uncover hidden power issues and give privilege to local knowledge/expertise by being attentive to body politics and geopolitics in technology design and research. Secondly, we argued that ArabHCI and AfriCHI communities have created intellectual spaces and mediums that could foster a decolonisation wave in $\mathrm{HCI} / \mathrm{CSCW}$ research and fulfill the need for local researchers to represent themselves without corroborating their credibility through Western eyes. In fact, despite the absence of the decolonisation terminology, we showed how evidence of decolonisation tendencies and concepts are present in the communities initiation documents, calls for participation, and published contributions. We would like to emphasise, however, that this is our own reading of the communities and not necessarily one that is promoted by the community founders nor is it necessarily adopted by community members. We complemented this argument by problematising the use of the term itself in the global HCI/CSCW community. Thirdly, we introduced three paradoxes as theoretical concepts to explain dilemmas faced by local researchers who wish to pursue decolonisation thinking and engage with the global $\mathrm{HCI} / \mathrm{CSCW}$ sphere, yet find themselves in an awkward insideroutsider position with respect to their local knowledge and communities. We base the paradoxes on our own cross-cultures work and lived experiences, embedded within our decolonisation practices, our engagement with both communities, and our critical engagement with the decolonisation literature. 
These contributions can hold a great significance for HCI and the CSCW community. The article advances the post-colonial discourse by highlighting the colonisation risk carried out in politically neutral postcolonial stances. While this is not a wholly original argument, it merits amplification as it is still often overlooked in ICT4D/HCI4D projects, which could benefit, we argue, from critical reflections on power dynamics among the research team, funders, and/or communities in the most of the published research. Further, the article brought visibility to the role played by locally-driven $\mathrm{HCI}$ communities, and it positioned them as potential drivers for a decolonisation wave in HCI/CSCW. Similarly to Bidwell (2016), we highlighted the communities dissatisfaction of their current representation in the Global $\mathrm{HCI} / \mathrm{CSCW}$ research. Nonetheless, our work extends Bidwell's by unpacking the complexities surrounding the use of the term "decolonisation". We problematised the use of the term in the terminology paradox by bringing forward the primary voices of the authors and of other members of the AfriCHI and ArabHCI communities. Framing the use of the term "decolonisation" in the terminology paradox bears a certain significance as this political stance was assigned rather than originating from the periphery.

The article also advances the decolonisation discourse by highlighting the practical dilemmas faced by local researchers who wish to pursue decolonisation endeavours individually or collaboratively with Western researchers. In line with Ali (2016), we brought to the fore the interplay of body politics (deconstructing the bodies involved in research) and the geopolitics (interrogating the origins and destination of research agendas, the knowledge generation, and application) to reveal the nuances of the relationship of the local researchers to Western academic and publishing systems in the terminology and ethical paradox, and to their local communities in the micro-colonisation paradox.

As put by Zavala (2013), 'decolonizing research strategies are less about the struggle for method and more about the spaces that make decolonizing research' ( $\mathrm{p}$. 55). We did not focus on design methods as we are not attempting to prescribe nor advocate for a particular recipe of decolonisation methods. Nor do we think a decolonisation analytical lens is adequate for all $\mathrm{HCI} / \mathrm{CSCW}$ research. Rather, we believe that our article contributes to making decolonisation research possible in the global $\mathrm{HCI} / \mathrm{CSCW}$ communities by bringing awareness to the potential richness that such a lens could bring to collaborative $\mathrm{HCI} / \mathrm{CSCW}$ across borders and cultures.

\section{A Way Forward}

Through this article, we advocate for a decolonisation lens that is explicit and vocal about past and present biases, but we are also cognisant of the paradoxes it presents. We find it important that local and Western researchers interrogate and define their own meaning of decolonisation based on the context that they operate in, which should in turn be collectively defined within the community. Local researchers should be especially encouraged to engage with the term and add their voice to 
Western discourses. Open discussions on decolonisation and the paradoxes it represents is a required forerunner for local researchers to be key drivers and actors of decolonisation research. Avenues for such discussions should start with our own local research endeavours and outlets and span to the global sphere. Several opportunities to raise the above-mentioned concerns on decolonising $\mathrm{HCI}$ and nurturing such discussions include:

- HCI education. Teaching HCI at both school and tertiary levels are significant spaces for having critical discussions on a decolonial lens within HCI discourse. Having local communities themselves involved in informing the curriculum, driving research agendas, and proposing research topics are alternative ways to transform the education landscape in terms of addressing the issues we raised prior. Past attempts for catalysing an Afrocentric HCI curricular (Lazem and Dray 2018) and HCI educational events (Peters et al. 2019) are other suitable target venues for extending the discussion brought forward in this paper.

- Conferences, workshops, debates, and symposiums, etc. Local and international conferences bear opportunities to host workshops, debates, and symposiums with diverse researchers to have open discussions on decolonisation. Local researchers should be encouraged to propose conference tracks and themes centered on the different paradoxes raised earlier. These would serve as suitable venues to propose and or share practical solutions to these paradoxes. Moreover, the active engagement of the communities we engage in such discussions is paramount to pushing the decolonial agenda forward.

- Academic and non-academic publications. Researchers should be encouraged to share their work and experiences, especially when engaging with local contexts. A clear discussion on their stances, challenges, and approaches they took to overcome challenges are beneficial ways for us to grow as communities and become comfortable with addressing the issues we raised in this paper. The format of publications should not be limited to formal academic spaces but should include non-academic spaces and non written formats such that this discussion is more inclusive.

- Academic policy (paper reviews and ethics/Institutional review board (IRB) processes). AfriCHI/ArabHCI communities could develop guidelines for reviewers to apply a decolonisation approach to their reviewing work. However, it should not stop at the reviewer level but entire conferences and publication outlets need to be sensitised on the need for decolonisation. Beyond the review process, the ethics/IRB committees at local institutions should also be sensitised on decolonisation within $\mathrm{HCI}$ and the paradoxes that local researchers tend to face. Such committees should then drive researchers to critically reflect on their decolonial stances and how that influences or could influence the work they plan to embark on. 
When we do not engage with the term or the concept of decolonisation, our sense of agency could be easily diminished and we may perpetuate that to the community. We might run the risk of being under the influence of "foreign is good" while funders dictate the rules of engagement. Global South countries often find that they have limited choices because such funding agencies bankroll the projects and set the rules. Local researchers should also place more trust and appreciation in their indigenous knowledge systems and integrate this into their research work to localise methods and solutions. Furthermore, local researchers should start speaking more openly about power issues in their collaborations and partnerships. Researchers should also advocate that their local institutions review the terms of international collaboration. This will allow researchers to establish long-term relationships based on trust and mutual benefit.

We should develop a code of ethics for all researchers on how to engage with communities and apply the decolonisation lens. Flexibility, respect, and sensitivity towards the local context and local culture are the underlying components that will grow into long term engagement for communities, students, and researchers.

Indigenous knowledge is an important resource and we should utilise the tools and methods that we have at our disposal to enhance it. HCI Local researchers should take more responsibility for local technology design while advising government and donor communities. Another important aspect of decolonisation is that we have to recognise but dismantle the exotic "other" syndrome and instead base our engagement on shared values and morals. Taking ownership and control of our own agendas and setting the rules for the engagement is critical to avoid the risk of silencing important voices.

We believe AfriCHI/ArabHCI communities leadership will be instrumental in supporting local efforts by providing culturally sensitive outlets for local researchers to voice their concerns and discuss future plans and joint efforts.

Finally, we believe that we added a blended perspective to the narratives and sense-making of the decolonisation debate in HCI and CSCW. Our perspectives were informed by the AfriCHI and ArabHCI communities, the current literature, and our own outsider/insider lived experiences and personal narratives. This blended approach culminated in our call to researchers working with marginalised populations to examine their research work using a decolonisation lens. We believe that such an approach will begin to entrench mutual trust and respect as well as inclusivity into our research work especially when working in non-Western contexts.

Open Access This article is licensed under a Creative Commons Attribution 4.0 International License, which permits use, sharing, adaptation, distribution and reproduction in any medium or format, as long as you give appropriate credit to the original author(s) and the source, provide a link to the Creative Commons licence, and indicate if changes were made. The images or other third party material in this article are included in the article's Creative Commons licence, unless indicated otherwise in a credit line to the material. If material is not included in the article's 
Creative Commons licence and your intended use is not permitted by statutory regulation or exceeds the permitted use, you will need to obtain permission directly from the copyright holder. To view a copy of this licence, visit http:// creativecommons.org/licenses/by/4.0/.

\section{References}

Abokhodair, Norah; Sofiane Abbar; Sarah Vieweg; and Yelena Mejova (2016). Privacy and Twitter in Qatar: Traditional Values in the Digital World. In: WebSci '16. Proceedings of the $8^{\text {th }}$ ACM Conference on Web Science, Hannover, Germany, May 2016. New York: ACM Press, pp. 66-77.

Abokhodair, Norah; Adam Hodges; and Sarah Vieweg (2017). Photo Sharing in the Arab Gulf. In: CSCW '17. Proceedings of the 2017 ACM Conference on Computer Supported Cooperative Work and Social Computing, Portland, Oregon, USA, February 2017. New York: ACM Press, pp. 696711.

Adamu, Muhammad Sadi (2016). Developing a Mobile Learning App: A User-Centric Approach. In: AfriCHI '16. Proceedings of the First African Conference for Human Computer Interaction, Nairobi, Kenya, November 2016. New York: ACM Press, pp. 139-143.

Ahmed, Syed Faiz; Pratyasha Saha; and S. M. Taiabul Haque (2020). Technology Adoption Dynamics of the Press Workers in Bangladesh. In: COMPASS '20. Proceedings of the $3^{\text {rd }}$ ACM SIGCAS Conference on Computing and Sustainable Societies, June 2020. New York: ACM Press, pp $148-159$.

Alabdulqader, Ebtisam; Norah Abokhodair; and Shaimaa Lazem (2017). Designing for the Arab World. In: DIS '17 Companion. Proceedings of the 2017 ACM Conference Companion Publication on Designing Interactive Systems, Edinburgh, United Kingdom, June 2017. New York: ACM Press, pp. 348-351.

Alabdulqader, Ebtisam; Shaimaa Lazem; Mohamed Khamis; and Susan M. Dray (2018). Exploring Participatory Design Methods to Engage with Arab Communities. In: CHI EA '18. Extended Abstracts of the 2018 CHI Conference on Human Factors in Computing Systems, Montreal QC, Canada, April 2018. New York: ACM Press, paper no. W27, pp. 1-8.

Alabdulqader, Ebtisam; Shaimaa Lazem; Soud Nassir; Mennatallah Saleh; Sara Armouch; and Susan Dray (2019). With an Eye to the Future: HCI Practice and Research in the Arab World. In: CHI EA '19. Extended Abstracts of the 2019 CHI Conference on Human Factors in Computing Systems, Glasgow, Scotland, UK, May 2019. New York: ACM Press, pp. 1-9.

Al-Dawood, Adel; Norah Abokhodair; Houda El mimouni; and Svetlana Yarosh (2017). "Against Marrying a Stranger": Marital Matchmaking Technologies in Saudi Arabia. In: DIS '17. Proceedings of the 2017 ACM Conference on Designing Interactive Systems, Edinburgh, United Kingdom, June 2017. New York: ACM Press, pp. 1013-1024.

Ali, Mustafa (2014). Towards a decolonial computing. In: Ambiguous Technologies: Philosophical Issues, Practical Solutions, Human Nature. International Society of Ethics and Information Technology, pp. 28-35.

Ali, Syed Mustafa (2016). A Brief Introduction to Decolonial Computing. XRDS: Crossroads, the ACM Magazine for Students - Cultures of Computing, vol. 22, no. 4, Summer 2016, pp. 16-21.

Alshehri, Majdah; and Norman Makoto Su (2018). The Beauty of Ugliness: Preserving while Communicating Online with Shared Graphic Photos. Computer Supported Cooperative Work (CSCW), vol. 27, no. 3, pp. 355-388.

Amukugo, Karin; and Anicia Peters (2016). Citizen-Centric E-Government Services in Namibia: Myth or Reality. In: AfriCHI '16. Proceedings of the First African Conference for Human Computer Interaction, Nairobi, Kenya, November 2016, New York: ACM Press, pp. 193-197. 
Arawjo, Ian; Ariam Mogos; Steven J. Jackson; Tapan Parikh; and Kentaro Toyama (2019). Computing Education for Intercultural Learning: Lessons from the Nairobi Play Project. Proc. ACM Hum. Comput. Interact. vol. 3, no. CSCW, article 52, November 2019, pp. 1-24.

Asad, Miriam; and Christopher A. Le Dantec (2015). Illegitimate Civic Participation: Supporting Community Activists on the Ground. In: CSCW '15. Proceedings of the 18th ACM Conference on Computer Supported Cooperative Work \& Social Computing, Vancouver, BC, Canada, February 2015. New York: ACM Press, pp. 1694-1703.

Awori, Kagonya; Nicola J. Bidwell; Tigist Sherwaga Hussan; Satinder Gill; and Silvia Lindtner (2016a). Decolonising Technology Design. In: AfriCHI '16. Proceedings of the First African Conference for Human Computer Interaction, Nairobi, Kenya, November 2016. New York: ACM Press, pp. 226-228.

Awori, Kagonya; Frank Vetere; and Wally Smith (2016b). Sessions with Grandma: Fostering Indigenous Knowledge Through Video Mediated Communication. In: AfriCHI '16. Proceedings of the First African Conference for Human Computer Interaction, Nairobi, Kenya, November 2016. New York: ACM Press, pp. 1-11.

Bardzell, Shaowen (2010). Feminist HCI: Taking Stock and Outlining and Agenda for Design. In: CHI '10. Proceedings of the 2010 CHI Conference on Human Factors in Computing Systems, Atlanta, Georgia, USA, April 2010. New York: ACM Press, pp. 1301-1310.

Bardzell, Jeffrey; and Shaowen Bardzell (2016). Humanistic HCI. Interactions, vol. 23, no. 2, pp. 20 29.

Battiste, Marie (2005). Indigenous Knowledge: Foundations for First Nations. WINHEC: International Journal of Indigenous Education Scholarship, no. 1, January 2005, pp. $1-17$.

Bayor, Andrew; Cliff Schmidt; Fidelis Dauri; Noel Wilson; Christopher Drovandi; and Margot Brereton (2018). The Talking Book: Participatory Design of an Icon-Based User Interface for Rural People with Low Literacy. In: AfriCHI '18. Proceedings of the Second African Conference for Human Computer Interaction, Windhoek, Namibia, December 2018. New York: ACM Press. article no. 3, pp. 1-10

Belay, Elefelious Getachew; D. Scott McCrickard; and Solomon Atnafu Besufekad (2016). Designing Mobile Interaction for Low-Literacy (D-MILL). In: AfriCHI '16. Proceedings of the First African Conference for Human Computer Interaction, Nairobi, Kenya, November 2016. New York: ACM Press, pp. 251-255.

Berzowska, Joanna; Aisling, Kelliher; Daniela K. Rosner; Matt Ratto; Suzanne Kite (2019). Critical Materiality: Creating Toolkits and Methods for Engaging Materiality in HCI. In: TEL '19. Proceedings of the 13th International Conference on Tangible, Embedded, and Embodied Interaction, Tampe, Arizona, USA, 17-20 March 2019. New York: ACM Press, pp. 691-694.

Betts, Raymond F. (2012). Decolonization. A Brief History of the Word. In E. Bogaerts and R. Raben (eds): The Decolonization of African and Asian Societies, 1930s-1970s. Amsterdam, Netherlands: Brill, pp. 23-37.

Bidwell, Nicola J. (2016). Decolonizing HCI and Interaction Design Discourse: Some Considerations in Planning AfriCHI. XRDS: Crossroads, the ACM Magazine for Students - Cultures of Computing, vol. 22, no. 4, Summer 2016, pp. 22-27.

Bishop, Russell (2005). Freeing Ourselves from Neo-Colonial Domination in Research: A Kaupapa Māori Approach to Creating Knowledge. In N. K. Denzin and Y. S. Lincoln (eds): The SAGE Handbook of Qualitative Research. Thousand Oaks, California: SAGE Publications, pp. 109-138.

Bjørn, Pernille; Luigina Ciolfi; Mark Ackerman; Geraldine Fitzpatrick; and Volker Wulf (2016). Practice-based CSCW research: ECSCW bridging across the Atlantic. In: CSCW '16 Companion. Proceedings of the $19^{\text {th }}$ ACM Conference on Computer Supported Cooperative Work and Social Computing Companion, San Francisco, California, USA, February 2016. pp. 210-220. 
Bonn, Julius Moritz (1938). The Crumbling of Empire: The Disintegration of World Economy. London: G. Allen \& Unwin Ltd.

Boveda, Mildred; and Kakali Bhattacharya (2019). Love as De/Colonial Onto-Epistemology: A PostOppositional Approach to Contextualized Research Ethics. The Urban Review, vol. 51, no. 1, pp. 5 -25 .

Bratteteig, Tone; and Ina Wagner (2016). Unpacking the Notion of Participation in Participatory Design. Computer Supported Cooperative Work (CSCW), vol. 25, no. 6, pp. 425-475.

Buskens, Ineke; and Mirjam van Reisen (2017). Theorising Agency in ICT4D: Epistemic Sovereignty and Transformation-in-Connection. In M. Mawere (ed): Underdevelopment, Development and the Future of Africa. Langaa RPCIG, pp. 461-498.

Carbonnier, Gilles; and Tiina Kontinen. (2014). North-South Research Partnerships: Academia Meets Development?. Bonn: European Association of Development Research and Training Institutes (EADI).

Chancellor, Stevie; Shion Guha; Jofish Kaye; Jen King; Niloufar Salehi; Sarita Schoenebeck; and Elizabeth Stowell (2019). The Relationships Between Data, Power, and Justice in CSCW Research. In: CSCW '19 Companion. Conference Companion Publication of the 2019 ACM Conference on Computer Supported Cooperative Work and Social Computing, Austin, TX, USA, November 2019. New York: ACM Press, pp. 102-105.

Cochran, Patricia A. L.; Catherine A. Marshall; Carmen Garcia-Downing; Elizabeth Kendall; Doris Cook; Laurie McCubbin; and Reva Mariah S. Gover (2008). Indigenous Ways of Knowing: Implications for Participatory Research and Community. American Journal of Public Health, vol. 98 , no. 1 , pp. 22-27.

Collins, Patricia Hill (1998). Fighting Words. Black Women \& The Search for Justice. Minneapolis, Minnesota: University of Minnesota Press.

Datta, Ranjan (2018). Decolonizing Both Researcher and Research and its Effectiveness in Indigenous Research. Research Ethics, vol. 14, no. 2, September 2018, pp. 1-24.

de O. Martins, Luiza P.; and Pedro J. S. Vieira de Oliveira (2016). Breaking the Cycle of Macondo: Design and Decolonial Futures. XRDS: Crossroads, the ACM Magazine for Students - Cultures of Computing, vol. 22, no. 4, Summer 2016, pp. 28-32.

Dell, Nicola; and Neha Kumar (2016). The Ins and Outs of HCI for Development. In: CHI '16. Proceedings of the 2016 CHI Conference on Human Factors in Computing Systems, San Jose, California, USA, 7-12 May 2016. New York: ACM Press, pp. 2220-2232.

Denzin, Norman K.; and Yvonna S. Lincoln (2008). Introduction: Critical Methodologies and Indigenous Inquiry. In N. K. Denzin, Y. S. Lincoln, and L. T. Smith (eds): Handbook of Critical and Indigenous Methodologies. Thousand Oaks, California: SAGE Publications, pp. 1-20.

Dosono, Bryan; and Bryan Semaan (2020). Decolonizing Tactics as Collective Resilience: Identity Work of AAPI Communities on Reddit. Proc. ACM Hum.-Comput. Interact. vol. 4, no. CSCW1, article. 069, May 2020, pp. 1-20.

Dourish, Paul; and Scott D. Mainwaring (2012). Ubicomp's Colonial Impulse. In: UbiComp '12. Proceedings of the 2012 ACM Conference on Ubiquitous Computing, Pittsburgh, Pennsylvania, 58 September 2012. New York: ACM Press, pp. 133-142.

Du, Jia Tina (2017). Research on Indigenous People and the Role of Information and Communications Technology in Development: A Review of the Literature. Journal of the Australian Library and Information Association, vol. 66, no. 4, pp. 344-363.

Fox, Sarah; Jill Diamond; Lilly Irani; Tad Hirsch; Michael Muller; and Shaowen Bardzell (2017). Social Justice and Design: Power and Oppression in Collaborative Systems. In: CSCW '17 Companion. Conference Companion Publication of the 2017 ACM Conference on Computer Supported Cooperative Work \& Social Computing, Portland, Oregon, USA, February 2017. New York: ACM Press, pp. 117-122. 
Gallert, Peter; Heike Winschiers-Theophilus; Gereon K. Kapuire; Colin Stanley; Daniel G. Cabrero; and Bobby Shabangu (2016). Indigenous Knowledge for Wikipedia: A Case Study with an OvaHerero Community in Eastern Namibia. In: AfriCHI '16. Proceedings of the First African Conference for Human Computer Interaction, Nairobi, Kenya, November 2016. New York: ACM Press, pp. 155-159.

Ghaznavi, Ibrahim; Shan Randhawa; Usman Shadid; Bilal Saleem; and Umar Saif (2016). Speakmytext: A Platform to Support Crowd-Sourced Text-to-Audio Translations. In: AfriCHI '16. Proceedings of the First African Conference for Human Computer Interaction, Nairobi, Kenya, November 2016. New York: ACM Press, pp. 160-164.

Ghosh, Ishita; and Jacki O'Neill (2020). The Unbearable Modernity of Mobile Money. Computer Supported Cooperative Work (CSCW). vol. 29, no. 3, pp. 227-261.

Giglitto, Danilo; Shaimaa Lazem; and Anne Preston (2018). In the Eye of the Student: "An Intangible Cultural Heritage Experience, with a Human-Computer Interaction Twist". In: CHI '18. Proceedings of the 2018 CHI Conference on Human Factors in Computing Systems, Montreal QC, Canada, April 2018. New York: ACM Press, paper no. 290, pp 1-12.

Le Grange, Lesley (2016). Decolonising the University Curriculum. South African Journal of Higher Education, vol. 30 , no. 2, pp. 1-12.

Grosfoguel, Ramón (2002). Colonial Difference, Geopolitics of Knowledge, Global Coloniality in the Modern/Colonial Capitalist World-System. Review (Fernand Braudel Center), vol. 25, no .3, pp. 203-224.

Hajibayova, Lala; and Wayne Buente (2016). Representation of Indigenous Culture: Considering the Hawaiian Hula. Journal of Documentation, vol. 73, no. 6, pp. 1137-1148.

Hajibayova, Lala; Wayne Buente; Luz Quiroga; and Shanye Valeho-Novikoff (2016). Representation of Kanala Maoli (Hawaiian) Culture: A Case of Hula Dance. Proceedings of the Association for Information and Science and Technology, vol. 53, no. 1, pp. 1-3.

Hamidi, Foad; Patrick Mbullo; Deurence Onyango; Michaela Hyinie; Susan McGrath; and Melanie Baljko (2018). Participatory Design of DIY Digital Assistive Technology in Western Kenya. In: AfriCHI '18. Proceedings of the Second African Conference for Human Computer Interaction, Windhoek, Namibia, December 2018. New York: ACM Press. article no 8, pp. 1-11.

Irani, Lilly C.; and Paul Dourish (2009). Postcolonial Interculturality. In: IWIC '09. Proceedings of the 2009 International Workshop on Intercultural Collaboration, Palo Alto, California, USA, Februray 2009. New York: ACM Press, pp. 249-252.

Irani, Lilly; Janet Vartesi; Paul Dourish; Kavita Philip; and Rebecca E. Ginter (2010). Postcolonial Computing: A Lens on Design and Development. In: CHI '10. Proceedings of the 2010 CHI Conference on Human Factors in Computing Systems, Atlanta, Georgia, USA, April 2010. New York: ACM Press, pp. 1011-1320.

Itenge, Helvi; and Heike Winschiers-Theophilus (2018). People's Primary School Interactive Tech Library Exhibition. In: AfriCHI '18. Proceedings of the Second African Conference for Human Computer Interaction, Windhoek, Namibia, December 2018. New York: ACM Press, article no. 64, pp. 1-4.

Jere, Nobert; Ndafaha Mungonena; and Anicia Peters (2016). Social Media Usage in Africa and its Ethical Implications. In: AfriCHI '16. Proceedings of the First African Conference for Human Computer Interaction, Nairobi, Kenya, November 2016. New York: ACM Press, pp. 263-266.

Jordan, Zayira; Jose Abdelnour Nocera; Anicia Peters; Susan Dray; and Stephen Kimani (2016). A Living HCI Curriculum. In: AfriCHI '16. Proceedings of the First African Conference for Human Computer Interaction, Nairobi, Kenya, November 2016. New York: ACM Press, pp. 229-232.

Kapuire, Gereon Koch; Heike Winschiers-Theophilus; and Edwin Blake (2015). An Insider Perspective on Community Gains: A Subjective Account of a Namibian Rural Communities perception of a Long-Term Participatory Design Project. International Journal of Human Computer Studies, vol. 74, February 2015, pp. 124-143. 
Katusiime, Jane; and Niels Pinkwart (2016). Supporting Maternal Health Education in Developing Countries Using Mobile Phones-Results of a Pilot Study. In: AfriCHI '16. Proceedings of the First African Conference for Human Computer Interaction, Nairobi, Kenya, November 2016. New York: ACM Press, pp. 48-57.

Kauhondamwa, Maria; Heike Winschiers-Theophilus; Simson Kapembe; Hiskia Costa; Jan Guxab; Isay Kamati; and Helena Afrikaner (2018). Co-Creating Personal Augmented Reality Accessories to Enhance Social Well-Being of Urban San Youth. In: AfriCHI '18. Proceedings of the Second African Conference for Human Computer Interaction, Windhoek, Namibia, December 2018. New York: ACM Press, article no. 10, pp. 1-10.

Kawu, Abdullahi Abubakar; Rita Orji; Aisha Awal; and Usman Gana (2018). Personality, Culture and Password Behaviour. In: AfriCHI '18. Proceedings of the Second African Conference for Human Computer Interaction, Windhoek, Namibia, December 2018. New York: ACM Press. article no. 36, pp. 1-4.

Keyes, Os; Josephine Hoy; and Margaret Drouhard (2019). Human-Computer Insurrection: Notes on an Anarchist HCI. In: CHI '19. Proceedings of the 2019 CHI Conference on Human Factors in Computing Systems, Glasgow, Scotland, UK, May 2019. New York: ACM Press. paper no. 339, pp $1-13$.

Khovanskaya, Vera; Lynn Dombrowski; Jeffrey Rzeszotarski, and Phoebe Sengers (2019). The Tools of Management: Adapting Historical Union Tactics to Platform-Mediated Labor. Proc. ACM Hum.-Comput. Interact. vol. 3, no. CSCW, November 2019, article no. 208, pp. 1-22.

Klose, Fabian (2014). Decolonization and Revolution. European History Online, July 2014. http://iegego.eu/en/threads/europe-and-the-world/european-overseas-rule/fabian-klose-decolonization-andrevolution. Accessed 23 May 2021.

Kou, Yubo; Colin M. Gray; Austin Toombs; and Bonnie Nardi (2018). The Politics of Titling: The Representation of Countries in CHI Papers. In: CHI EA '18. Extended Abstracts of the 2018 CHI Conference on Human Factors in Computing Systems, Montreal QC, Canada, April 2018. New York: ACM Press. paper no. alt16, pp 1-10.

Kumar, Neha; Naveena Karusala; Azra Ismail; Marisol Wong-Villacres; and Aditya Vishwanath (2019). Engaging Feminist Solidarity for Comparative Research, Design, and Practice. Proc. ACM Hum.-Comput. Interact. vol. 3, no. CSCW, November 2019, article no. 167, pp 1-24.

Lazem, Shaimaa (2019). Championing HCI Education to CS Undergraduates at a Grassroots Level: A Case Study in Egypt. Journal of Usability Studies, vol. 15, no. 1, November 2019, pp. 8-22.

Lazem, Shaimaa; and Susan Dray (2018). Baraza! Human-Computer Interaction Education in Africa. Interactions, vol. 25, no. 2, pp. 74-77.

Lazem, Shaimaa; and Hussein Aly Jad (2017). We Play We Learn: Exploring the Value of Digital Educational Games in Rural Egypt. In: CHI '17. Proceedings of the 2017 CHI Conference on Human-Factors in Computing Systems, Denver, Colorado, USA, May 2017. New York: ACM Press, pp. 2782-2791.

Lazem, Shaimaa; Ebtisam Alabdulqader; and Mohamed Khamis (2019). Introduction to Special Topic: HCI in the Arab World. Interactions, vol. 26, no. 3, pp. 41-43.

Mahmoud, Ahmed Hamdy; Yara Abdullatif; and Shaimaa Lazem (2018). PI Floor: Portable Interactive Floor with High Resilience and Minimal Setup for Edutainment. In: MUM 2018. Proceedings of the $17^{\text {th }}$ International Conference on Mobile and Ubiquitous Multimedia, Cairo, Egypt, November 2018. New York: ACM Press, pp. 419-423.

Martin, David; Jacki O’Neill; Neha Gupta; and Benjamin V. Hanrahan (2016). Turking in a Global Labour Market. Computer Supported Cooperative Work (CSCW), vol. 25, no. 1, pp. 39-77.

Mawere, Minyaradzi; and Samuel Awuah-Nyamekye (2015). Between Rhetoric and Reality: The State and Use of Indigenous Knowledge in Post-Colonial Africa. Bamenda, Cameroon: Langaa RPCIG. 
Mawere, Minyaradzi; and Gertjan van Stam (2015). Paradigm Clash, Imperial Methodological Epistemologies and Development in Africa: Observations from Rural Zimbabwe and Zambia. In M. Mawere and T. R. Mwanaka (eds): Democracy, Good Governance and Development in Africa, Mankon, Bamenda: Langaa RPCIG, pp. 193-212.

Mawere, Minyaradzi; and Gertjan van Stam (2019). Research in Africa for Africa? Probing the Effect and Credibility of Research Done by Foreigners for Africa. In P. Nielsen and H. Kimaro (eds): Information and Communication Technologies for Development. Strengthening Southern-Driven Cooperation as a Catalyst for ICT4D. Cham, Switzerland: Springer, pp. 168-179.

Mgala, Mvurya; Hussein Suleman; and Audrey Mbogho (2016). Undereducation, Motivating Intervention in Rural Schools with MAPPS. In: AfriCHI '16. Proceedings of the First African Conference for Human Computer Interaction, Nairobi, Kenya, November 2016. New York: ACM Press, pp. 203-207.

Mignolo, Walter D. (2012). Local Histories/Global Designs Coloniality, Subaltern Knowledges, and Border Thinking. Princeton, New Jersey: Princeton University Press.

Molapo, Maletsabisa; Melissa Densmore; and Limpho Morie (2016). Designing with Community Health Workers: Enabling Productive Participation Through Exploration. In: AfriCHI '16. Proceedings of the First African Conference for Human Computer Interaction, Nairobi, Kenya, November 2016. New York: ACM Press, pp. 58-68.

Morshed, Mehrab Bin; Michaelanne Dye; Syed Ishtiaque Ahmed; and Neha Kumar (2017). When the internet goes down in Bangladesh. In: CSCW'17. Proceedings of the 2017 ACM Conference on Computer Supported Cooperative Work and Social Computing, Portland Oregon, USA, February 2017, New York: ACM Press, pp. 1591-1604.

Muralidhar, Srihari Hulikal; Claus Bossen; and Jacki O'Neill (2019). Rethinking Financial Inclusion: from Access to Autonomy. Computer Supported Cooperative Work (CSCW), vol. 28, no. 3, pp. 511-547.

Mutua, Kagendo; and Beth Blue Swadener (2004). Introduction. In K. Mutua; and B. B. Swadener (eds): Decolonizing Research in Cross-Cultural Contexts: Critical Personal Narratives. Albany, New York: State University of New York Press, pp. 1-23.

Namara, Moses; Daricia Wilkinson; Byron M. Lowens; Bart P. Knijnenburg; Rita Orji; and Remy L. Sekou (2018). Cross-Cultural Perspectives on eHealth Privacy in Africa. In: AfriCHI '18. Proceedings of the Second African Conference on Human-Factors in Computing Systems, Windhoek, Namibia, December 2018. New York: ACM Press. article no. 7, pp. 1-11.

Nassir, Soud; and Tuck Wah Leong (2017). Traversing Boundaries: Understanding the Experiences of Ageing Saudis. In: CHI '17. Proceedings of the 2017 CHI Conference on Human-Factors in Computing Systems, Denver, Colorado, USA, May 2017. New York: ACM Press, pp. 6386-6397.

Nkwo, Makuochi (2019). Designing Culturally-Appropriate Persuasive Technology to Promote Positive Work Attitudes among Workers in Public Workplaces. In: UMAP '19. Proceedings of the $27^{\text {th }}$ ACM Conference on User Modeling, Adaptation and Personalization, Larnaca, Cyprus, June 2019. New York: ACM Press, pp. 345-348.

Nkwo, Makuochi; and Rita Orji (2018). Persuasive Technology in African Context: Deconstructing Persuasive Techniques in an African Online Marketplace. In: AfriCHI '18. Proceedings of the Second African Conference for Human Computer Interaction, Windhoek, Namibia, December 2018. New York: ACM Press. article no. 9, pp 1-10.

Nkwo, Makuochi; and Rita Orji (2019). Socially Responsive eCommerce Platforms: Design Implications for Online Marketplaces in Developing African Nation. In: UMAP '19 Adjunct. Adjunct Publication of the $27^{\text {th }}$ Conference on User Modeling, Adaptation and Personalization, Larnaca, Cyprus, June 2019. New York: ACM Press, pp. 57-62.

Nkwo, Makuochi; Rita Orji; and John Ugah (2018). Persuasion for Promoting Clean and Sustainable Environment. In: AfriCHI '18. Proceedings of the Second African Conference for Human 
Computer Interaction, Windhoek, Namibia, December 2018. New York: ACM Press, article no. 19, pp. 1-5.

Ntuli, P. Pitika (2002). Indigenous Knowledge Systems and the African Renaissance. In C. A. Odora Hoppers (ed): Indigenous Knowledge and the Integration of Knowledge Systems: Towards a Philosophy of Articulation. Claremont, South Africa: New Africa Books, pp. 53-66.

Ogbonnaya-Ogburu, Ihudiya Finda; Angela D. R. Smith; Alexandra To; and Kentaro Toyama (2020). Critical Race Theory for HCI. In CHI '20. Proceedings of the 2020 CHI Conference on Human Factors in Computing Systems, April 2020. New York: ACM Press, pp. 1-16.

Oguamanam, Vanessa; and Mary Gansallo (2016). LEDz and Cocktailz. In: AfriCHI '16. Proceedings of the First African Conference for Human Computer Interaction, Nairobi, Kenya, November 2016. New York: ACM Press, pp. 260-262.

Peters, Anicia; Zayira Jordan; Luiz Merkle; Mario Moreno Rocha; Jose Abdelnour Nocera; Gerrit C. van der Veer; Susan Dray; Jennifer Preece; Elizabeth Churchill (2016). Teaching HCI: A Living Curriculum. In: AfriCHI '16. Proceedings of the First African Conference for Human Computer Interaction, Nairobi, Kenya, November 2016. New York: ACM Press, pp. 267-279.

Peters, Anicia; Mthoko, Hafeni; Lazem, Shaimaa; Winschiers-Theophilus, Heike; and Maletsabisa Molapo (2019). My Heart is in Havana: Designing with Marginalized African Communities. Interactions, vol. 26, no. 5, pp. 86-88.

Philip, Kavita; Lilly Irani; and Paul Dourish (2012). Postcolonial Computing: A Tactical Survey. Science Technology and Human Values, vol. 37, no. 1, pp. 3-29.

Reitsma, Lizette; Ann Light; Tariq Zaman; and Paul Rodgers (2019). A Respectful Design Framework. Incorporating indigenous knowledge in the design process. The Design Journal, vol. 22, no. sup1, pp. 1555-1570.

Rey-Moreno, Carlos; Zukile Roro; William D. Tucker; Masbulele Jay Siya; Nicola J. Bidwell, and Javier Simo-Reigadas (2013). Experiences, Challenges and Lessons from Rolling Out a Rural WiFi Mesh Network. In ACM DEV '13. Proceedings of the $3^{\text {rd }}$ ACM Symposium on Computing for Development, Bangalore, India, 11-12 January 2013. New York: ACM Press, article no 11, pp. 110.

Said, Edward W. (2014). Orientalism. London: the Penguin Group (first published 1978).

Saleh, Mennatallah; and Christian Sturm (2018). Exploring the Effect of Literacy on Signs in GUI Design. In: AfriCHI '18. Proceedings of the Second African Conference for Human Computer Interaction. New York: ACM Press, article no. 21, pp. 1-5.

Saleh, Mennatallah; Mohamed Khamis; and Christian Sturm (2019). What About my Privacy, Habibi? Understanding Privacy Concerns and Perceptions of Users from Different Socioeconomic Groups in the Arab World. In D. Lamas; F. Loizides; L. Nacke; H. Petrie; M. Winckler; and P. Zaphiris (eds): INTERACT 2019. Proceedings of the 17th IFIP TC.13 International Conference on Human-Computer Interaction, Part III. Paphos, Cyprus, 02-06 September 2019, Springer International Publishing. pp. 67-87.

Sambasivan, Nithya; and Jess Holbrook (2019). Towards Responsible AI for the Next Billion Users. Interactions, vol. 26, no. 1, pp. 68-71.

Sandoval, Chela (2000). Methodology of the Oppressed (Theory Out of Bounds). Minneapolis, Minnesota: University of Minnesota Press.

Schlesinger, Ari; W. Keith Edwards; and Rebecca E. Grinter (2017). Intersectional HCI: Engaging Identity through Gender, Race, and Class. In: CHI '17. Proceedings of the 2017 CHI Conference on Human Factors in Computing Systems, Denver, Colorado, USA, 6-11 May 2017. New York: ACM Press, pp. 5412-5427.

Sium, Aman; Chandni Desai; and Eric Ritskes (2012). Towards the 'Tangible Unknown'. Decolonization: Indigeneity, Education \& Society, vol. 1, no. 1, pp. I-XIII.

Smith, Linda Tuhiwai (1999). Decolonizing Methodologies: Research and Indigenous People. London, UK: Zed Books Ltd and Dunedin, New Zealand: University of Otago Press. 
Smith, Andrew Cyrus; Nomusa Dlodlo; and Nobert Jere (2016). Towards an Internet of Things Tangible Program Environment Supported by Indigenous African Artefacts. In: AfriCHI '16. Proceedings of the First African Conference for Human Computer Interaction. New York: ACM Press, pp. 176-181.

Smith, Rachel Charlotte; Heike Winschiers-theophilus; Asnath Paula Kambunga; and Sarala Krishnamurthy. (2020). Decolonizing Participatory Design: Memory Making in Namibia. In PDC '20. Proceedings of the $16^{\text {th }}$ PDC '20. Proceedings of Participatory Design Conference, Manizales, Colombia, 15-19 June 2020. New York: ACM Press. pp. 96-106.

Ssozi-Mugurura, Fiona; Thomas Retmaier; Anja Venter; and Edwin Blake (2016). Enough with 'InThe-Wild'. In: AfriCHI '16. Proceedings of the First African Conference for Human Computer Interaction, Nairobi, Kenya, November 2016. New York: ACM Press, pp. 182-186.

Tamarkin, Noah (2011). Religion as Race, Recognition as Democracy: Lemba "Black Jews" in South Africa. The Annals of the American Academy of Political and Social Science, vol. 637, no. 1, pp. $148-164$.

Taylor, Jennifer Lawrence; Alessandro Soro; Anita Lee Hong; Paul Roe; and Margot Brereton (2016). Designing for Cross-Cultural Perspectives of Time. In: AfriCHI '16. Proceedings of the First African Conference for Human Computer Interaction, Nairobi, Kenya, November 2016. New York: ACM Press, pp. 219-224.

Therias, Emeline; Jon Bird; and Paul Marshall (2015). Más Tecnologia, Más Cambio?: Investigating an Educational Technology Project in Rural Peru. In: CHI 15. Proceedings of the $33^{\text {rd }}$ Annual ACM Conference on Human Factors in Computing Systems, Seoul, Republic of Korea, April 2015. New York: ACM Press, pp. 447-456.

Torretta, Nicholas B.; and Lizette Reitsma (2019). Design, Power and Colonisation: Decolonial and Antioppressive Explorations on Three Approaches for Design for Sustainability. In: ADIM2019. Proceedings of the Academy for Design Innovation Management Conference, London, United Kingdom, 18-21 June 2019. pp 1-10.

Tuck, Eve; and K. Wayne Yang (2012). Decolonization Is Not a Metaphor. Decolonization: Indigeneity, Education \& Society, vol. 1, no. 1, September 2012, pp. 1-40.

Uchidiuno, Judith; Evelyn Yarzebinski; Michael Madaio; Nupur Maheshwari; Ken Koedinger; and Amy Ogan (2018). Designing Appropriate Learning Technologies for School vs Home Settings in Tanzanian Rural Villages. In: COMPASS '18. Proceedings of the $1^{\text {st }}$ ACM SIGCAS Conference on Computing and Sustainable Societies, Menlo Park and San Jose, CA, USA, June 2018. New York: ACM Press, article no. 9, pp. 1-11.

Varanasi, Rama Adithya; Aditya Vashistha; Tapan Parikh; and Nicola Dell (2020). Challenges and Issues Integrating Smartphones into Teacher Support Programs in India. In: ICTD '20. Proceedings of the 2020 Information and Communication Technologies and Development, Guayaquil, Ecuador, 17-20 June 2020. New York: ACM Press. article no. 10, pp 1-11.

Walters, Karina L.; and Jane M. Simoni (2009). Decolonizing Strategies for Mentoring American Indians and Alaska Natives in HVI and Mental Health Research. American Journal of Public Health, vol. 99, no. suppl 1, pp. S71-S76.

Walton, Marion; Anja Venter; Thomas Reitmeyer; Maletšabisa Molapo; and Daniel G. Cabrero (2016). Gumzo: New Dialogues for HCI. In: AfriCHI '16. Proceedings of the First African Conference for Human Computer Interaction, Nairobi, Kenya, November 2016. New York: ACM Press, pp. 276-280.

Warrick, Elizabeth Muthoni; Tigist Shewarega Hussen; Jedidah Kibutu; and Bukelwa Ngoqo (2016). African Identity and HCI Methods that Inform Technology Design. In: AfriCHI '16. Proceedings of the First African Conference for Human Computer Interaction, Nairobi, Kenya, November 2016. New York: ACM Press, pp. 242-246.

Winschiers-Theophilus, Hieke; and Nicola J. Bidwell (2013). Toward an Afro-Centric Indigenous HCI Paradigm. International Journal of Human-Computer Interaction, vol. 29, no. 4, pp. 243-255. 
Winschiers-Theophilus, Heike; Shilumbe Chivuno-Kuria; Gereon Koch Kapuire; Nicola J. Bidwell; and Edwin Blake (2010). Being Participated: A Community Approach. In: PDC '10. Proceedings of the $11^{\text {th }}$ Biennial Participatory Design Conference, Sydney, Australia, November 2010. New York: ACM Press, pp. 1-10.

Winschiers-Theophilus, Hieke; Tariq Zaman; and Alvan Yeo (2015). Reducing "White Elephant" ICT4D Projects: A Community-Researcher Engagement. In: C\&T '15. Proceedings of the $7^{\text {th }}$ International Conference on Communities and Technology, Limerick, Ireland, 27-30 June 2015. New York: ACM Press, pp. 99-107.

Wyche, Susan (2020). Using Cultural Probes in HCI4D/ICTD: A Design Case Study from Bungoma, Kenya. Proc. ACM Hum.-Comput. Interact, vol. 4, no. CSCW1, article. 063, May 2020, pp. 1-23.

Yoo, Daisy; Odeth Kantengwa; Nick Logler; Reverien Interayamahanga; Joseph Nkurunziza; and Batya Friedman (2018). Collaborative Reflection: A Practice for Enriching Research Partnerships Spanning Culture, Discipline, and Time. In: CHI '18. Proceedings of the 2018 CHI Conference on Human Factors in Computing Systems, Montreal QC, Canada, April 2018. New York: ACM Press, article no. 279, pp. 1-11.

Zavala, Miguel (2013). What Do We Mean by Decolonizing Research Strategies? Lessons from Decolonizing, Indigenous Research Projects in New Zealand and Latin America. Decolonization: Indigeneity, Education \& Society, vol. 2, no. 1, pp. 55-71.

Publisher's Note Springer Nature remains neutral with regard to jurisdictional claims in published maps and institutional affiliations. 